INTERNATIONAL FOOD POLICY

RESEARCH INSTITUTE

sustainable solutions for ending hunger and poverty

IFPR ${ }^{\circledR}$ A member of the CGIAR consortium

IFPRI Discussion Paper 01224

November 2012

\title{
Improved Performance of Agriculture in Africa South of the Sahara \\ Taking Off or Bouncing Back
}

\author{
Alejandro Nin-Pratt \\ Michael Johnson \\ Bingxin Yu
}

Development Strategy and Governance Division 


\section{INTERNATIONAL FOOD POLICY RESEARCH INSTITUTE}

The International Food Policy Research Institute (IFPRI) was established in 1975 to identify and analyze national and international strategies and policies for meeting the food needs of the developing world on a sustainable basis, with particular emphasis on low-income countries and on the poorer groups in those countries. IFPRI is a member of the CGIAR Consortium.

\section{PARTNERS AND CONTRIBUTORS}

IFPRI gratefully acknowledges the generous unrestricted funding from Australia, Canada, China, Denmark, Finland, France, Germany, India, Ireland, Italy, Japan, the Netherlands, Norway, the Philippines, South Africa, Sweden, Switzerland, the United Kingdom, the United States, and the World Bank.

\section{AUTHORS}

Alejandro Nin-Pratt, International Food Policy Research Institute Research Fellow, Development Strategy and Governance Division A.NinPratt@cgiar.org

Michael Johnson, International Food Policy Research Institute Research Fellow, Development Strategy and Governance Division

Bingxin Yu, International Food Policy Research Institute

Research Fellow, Development Strategy and Governance Division

\section{Notices}

IFPRI Discussion Papers contain preliminary material and research results. They have been peer reviewed, but have not been subject to a formal external review via IFPRI's Publications Review Committee. They are circulated in order to stimulate discussion and critical comment; any opinions expressed are those of the author(s) and do not necessarily reflect the policies or opinions of IFPRI.

Copyright 2012 International Food Policy Research Institute. All rights reserved. Sections of this material may be reproduced for personal and not-for-profit use without the express written permission of but with acknowledgment to IFPRI. To reproduce the material contained herein for profit or commercial use requires express written permission. To obtain permission, contact the Communications Division at ifpri-copyright@cgiar.org. 


\section{Contents}

Abstract $\quad$ V

Acknowledgments vi

1. Introduction 1

2. Methodology 5

3. Results of Growth Decomposition 9

4. Explaining the Drivers of Growth 15

5. Summary Conclusion and Policy Implications 29

Appendix: Supplementary Tables 28

References $\quad 31$ 


\section{Tables}

1.1-Average annual growth rates in agriculture and overall GDP, 1961-2010 1

2.1-Definition of indexes for GDP decomposition when the GDP function is assumed to be of the translog functional form

3.1-Decomposition of AgGDP using accounting and parametric methods

3.2-AgGDP growth decomposition

3.3-AgGDP growth decomposition and growth performance of SSA countries, 2001-2010 (\%) 13

3.4-AgGDP growth decomposition and TFP and TOT growth performance of SSA countries, 2001-2010 (\%)

4.1-Average growth rates of total public agricultural $R \& D$ spending for different periods

4.2- Contribution of changes in crop output per hectare and total crop area in different countries to SSA's crop output growth, 2001-2010 (\%)

4.3- Share of different groups of commodities in total output of selected SSA countries

4.4 - Growth of AgGDP per capita in different periods (\%) sorted by growth in 2000-2009 27

4.5-Coefficients from regressions of AgGDP growth rates for different periods

A.1- Share of selected countries in agricultural production and resource use (percentage of total in SSA not including South Africa)

A.2-Estimation results of translog agricultural GDP equation

\section{Figures}

1.1-Evolution of agriculture value added in SSA 1965-2010 (developing countries only) 2

1.2-Change in public-sector resource flows to African agriculture, 1980-2010 3

1.3-Time series of global commodity price indexes and AgGDP, 1980 to $2012(1980=100) \quad 4$

3.1- Secular and shock components of TFP growth (22 SSA countries) 11

3.2-Evolution of different factors contributing to AgGDP growth in SSA, 1980-2010 (1994=1) 12

4.1-Trends in total public agricultural R\&D spending, 1981-2008 17

4.2-Cumulative agricultural growth between 2000 and 2010 due to R\&D investment 18

4.3-Comparative evolution of fertilizer use in SSA and South Asia (kilograms per hectare of cropland)

4.4-Evolution of the use of fertilizer in countries classified according to their TFP growth performance in 1995-2010 (kilograms per hectare) 20

4.5-Evolution of output per hectare, output, and crop area in SSA, 1970-2009 20

4.6-Evolution of labor productivity, output, and number of economically active population in agriculture in SSA, 1970-2009 (index 1970=1) 21

4.7-Growth path of agriculture land-labor productivity space (1970-2009) 21

4.8 - Contribution of changes in output per hectare and total crop area of different crops to individual SSA countries' output growth, 2001-2010 23

4.9-Evolution of an index of change in output composition (CSX) for agricultural production 24

4.10 - Trade openness of agriculture and evolution of the export/import ratio 26

4.11-Evolution of AgGDP per capita of rural population (simple average of AgGDP of 32 countries) 26

4.12 - Relationship between AgGDP per capita growth in 1975-1983 and growth in 2000-2010 28 


\begin{abstract}
The improved performance of the agricultural sector in Africa south of the Sahara during the most recent decade (2000-2010) has raised questions about the drivers behind the growth. Skeptics argue that rising commodity prices, as world markets experience a commodity boom, are the main cause of the agricultural growth. Others point to improvements in the policy environment and increased investments in agriculture at a time when African governments and donors have been rallying to increase their support to agriculture. Is African agriculture undergoing a new and sustained recovery after many decades of stagnant and volatile growth rates - or is it simply riding the current global commodity boom? We attempt to answer this question by analyzing the structure of overall agricultural growth in the past 30 years using a growth decomposition approach. Results show both good and bad news for future prospects of African agricultural growth. The good news is that a changing policy environment and increased attention to agriculture has had a major effect on overall productivity growth based on technical efficiency gains. The bad news is that most of this productivity growth is the result of countries recovering from the poor performance of the 1980s and 1990s together with favorable domestic prices. A key challenge for African countries in the years to come is to transform the current windfall gains from favorable high commodity prices and the one-time effects of policy reforms into sustainable growth based on technical change.
\end{abstract}

Keywords: Africa south of the Sahara, agriculture, productivity, growth accounting 


\section{ACKNOWLEDGMENTS}

The authors wish to thank Peter Hazell, as this paper is the result of a discussion we had with him early this year on the current situation and prospects for Africa. 


\section{INTRODUCTION}

For decades, the performance of the agricultural sector in Africa south of the Sahara (SSA) has been described as always lagging behind other developing regions (Kherallah et al. 2002; World Bank 2007). Although the sector has experienced periods of booms and busts, the boom periods have rarely been long enough to signify an important shift or take-off. Therefore, when the sector shows signs of a prolonged growth episode (no matter how modest), as in the most recent decade, we must ask whether the sector is undergoing a real economic take-off or just another temporary boom period due to higher global commodity prices.

The evidence of improved performance is indeed striking when compared with the past. For the first time, the agriculture sector has maintained a real growth rate of 3.4 percent per year, well above a population growth rate of about 2.5 percent (Table 1.1). Meanwhile, nominal growth rates have exceeded 10 percent, a growth rate last seen in the 1970s. Similarly, overall economic growth, as measured by annual changes in the gross domestic product (GDP), has been high at 5.2 percent per year.

Table 1.1-Average annual growth rates in agriculture and overall GDP, 1961-2010

\begin{tabular}{|c|c|c|c|c|c|}
\hline \multirow{2}{*}{\multicolumn{6}{|c|}{ a) AgGDP growth }} \\
\hline & & & & & \\
\hline Using 2000 constant US\$ & - & 2.3 & 2.2 & 3.4 & 3.4 \\
\hline Using current US\$ & 3.1 & 14.4 & 4.5 & -0.7 & 12.8 \\
\hline b) GDP growth & & & & & \\
\hline Using 2000 constant US\$ & 4.9 & 3.3 & 2.0 & 2.8 & 5.2 \\
\hline $\begin{array}{l}\text { Using current US } \$ \\
\text { c) Population growth }\end{array}$ & $\begin{array}{l}7.3 \\
2.5\end{array}$ & $\begin{array}{c}16.1 \\
2.8\end{array}$ & $\begin{array}{l}2.3 \\
2.8\end{array}$ & $\begin{array}{l}1.5 \\
2.6\end{array}$ & $\begin{array}{c}15.2 \\
2.5\end{array}$ \\
\hline
\end{tabular}

Source: World Bank (2012).

Note: $\quad \mathrm{GDP}=$ gross domestic product; $\mathrm{AgGDP}=$ agricultural gross domestic product.

To understand whether this prolonged period of growth in African agriculture is a sign of a real economic take-off, we need to know a little more about what has been driving it. An earlier examination of overall agricultural productivity growth by Nin Pratt and Yu (2008) concluded that much of the growth after the 1990s is best explained as a recovery or catch-up from past historical levels. They point to the efficiency gains realized from a wide range of policy and institutional reforms introduced as part of the structural adjustment programs of the 1980s and 1990s. The study, however, captured the trends in agricultural performance only to 2006. Since then, much has changed. The world continues to experience a global commodity price boom that shows no sign of ending soon, domestic markets have also seen higher prices, and there is increased attention to targeting public-sector investments to agriculture. Clearly, a reexamination of the underlying drivers of the current growth phenomenon is needed. In other words, how much of this growth is riding on the current global commodity boom? What have policy changes and public investment contributed to growth? Is growth the result of increased investment or more land and labor incorporated to agricultural production, or has it been fueled by growth in productivity? Undoubtedly, all of these explanations are plausible considering the trends in all three factors: an improved policy environment, increased public-sector resource flows, and a sustained rise in commodity prices. We review all three here briefly.

To begin with, work done in recent years (for example, Alene 2010; Block 1995, 2010; Fuglie and Rada 2011; Nin Pratt and Yu 2008) has helped to show how African agricultural performance improved in the aftermath of political, policy, and institutional reforms since the 1980s and 1990s, which reduced the heavy taxation on agriculture, increased the voices of civil society and farmers groups, and made governments more accountable. Figure 1.1 best illustrates this shift by comparing an average index measure of the rate of relative assistance (RRA) to agriculture with agriculture performance. Negative values of the index reflect unfavorable policies for agriculture, while values greater than zero reflect 
policies that favor agriculture relative to other sectors. As the figure shows, the index exhibits a high correlation with changes in agriculture value added (net output after subtracting intermediate inputs) over time (about 0.8). A simple regression of agriculture value added using RRA as independent variable results in a positive and significant coefficient for $\mathrm{RRA}\left(\mathrm{t}\right.$-statistic $=8.62$ and $\mathrm{R}^{2}$ of 0.66$)$.

Figure 1.1 - Evolution of agriculture value added in SSA 1965-2010 (developing countries only)

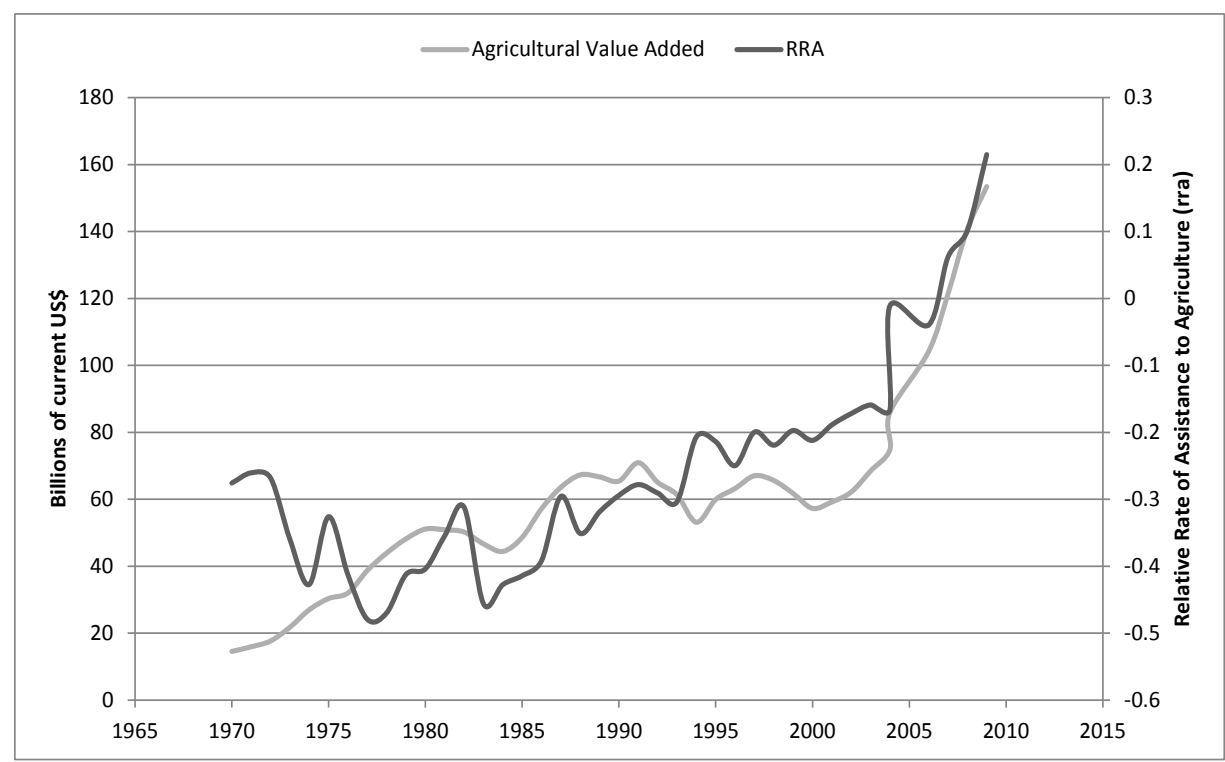

Source: Authors' calculations using data from World Bank (2012) and OECD Creditor Database (2012).

Notes: Relative rate of assistance to agriculture is calculated as RRA $=\left[\left(1+\mathrm{NRAag}^{\mathrm{t}}\right) /\left(1+\mathrm{NRAnonag}{ }^{\mathrm{t}}\right)\right]-1$, where NRA is the nominal rate of assistance.

$\mathrm{SSA}=$ Africa south of the Sahara.

With regard to public resource flows, those from African governments increased after 2003 and those from donors increased after 2006, as evident in Figure 1.2. This corresponds closely with the increasing trend of agricultural GDP after all values have been deflated to constant 2005 US dollars. The increase in government spending is likely to have had far greater effects than that of donors simply due to its much larger share of total public resources going into agriculture. However, this effect depends also on how efficiently the resources were ultimately allocated within agriculture. For many countries, for example, that has involved spending up to 70 percent on input subsidies for fertilizer (for example, Benin et al. 2011 for Ghana). Although still below levels seen in the 1980s, donors have nevertheless similarly increased their spending in African agriculture. It is therefore quite conceivable that such increased spending in agriculture may have had a direct impact on the sector's performance. 
Figure 1.2-Change in public-sector resource flows to African agriculture, 1980-2010

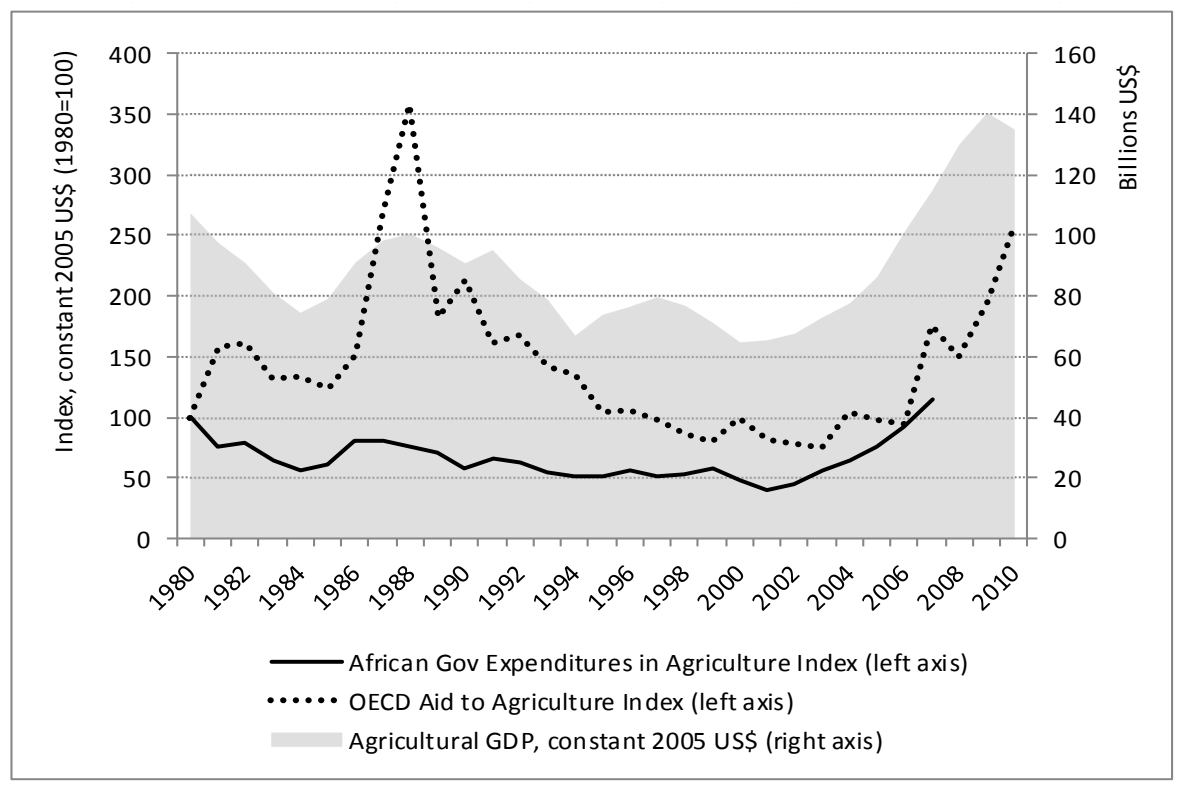

Source: Authors based on OECD (2012) for aid flows to agriculture across all countries in Africa south of the Sahara and ReSAKSS database on African agricultural expenditures for 13 countries for which data were available in the period 1980 to 2007: Botswana, Burkina Faso, Cameroon, Côte d'Ivoire, Ethiopia, Ghana, Kenya, Malawi, Mali, Niger, Togo, Uganda, and Zambia.

In addition to the increased support to agriculture, the period has also seen a trend of rising world commodity prices that has outlasted others in the past and shows no signs of falling at the present moment. Figure 1.3 illustrates the steady rise in commodity prices from the early 2000 s, even if we account for overall inflation. The world has experienced similar spikes before, particularly during the food and oil crises of the 1970s, but it has not sustained them for very long. Whereas countries that rely on primary commodity exports are benefiting from the global price boom, history shows that such a reliance on primary commodities can be a curse, as it produces booms and busts over the long run whenever world markets experience large price fluctuations. For example, after a spike in world prices for oil and non-oil commodities from 1973 to 1978, many African countries that initially benefited from the price rise were ill prepared to deal with rising debt costs in the 1980s after overborrowing during the boom years. This is not to say that the impact of primary commodity exports is all bad. On the contrary, as others have also pointed out (see Deaton 1999), because SSA remains abundant in natural resources relative to labor, it still has a comparative advantage in exporting primary commodities. Therefore, a practical goal for many of the affected countries is to learn how to better manage the booms in ways that allow them to be more resilient when the price boom period ends. 
Figure 1.3-Time series of global commodity price indexes and AgGDP, 1980 to $2012(1980=100)$

\section{(a) Based on constant values (constant 2005 US\$ $\quad$ (b) Based on nominal values (current US\$)}

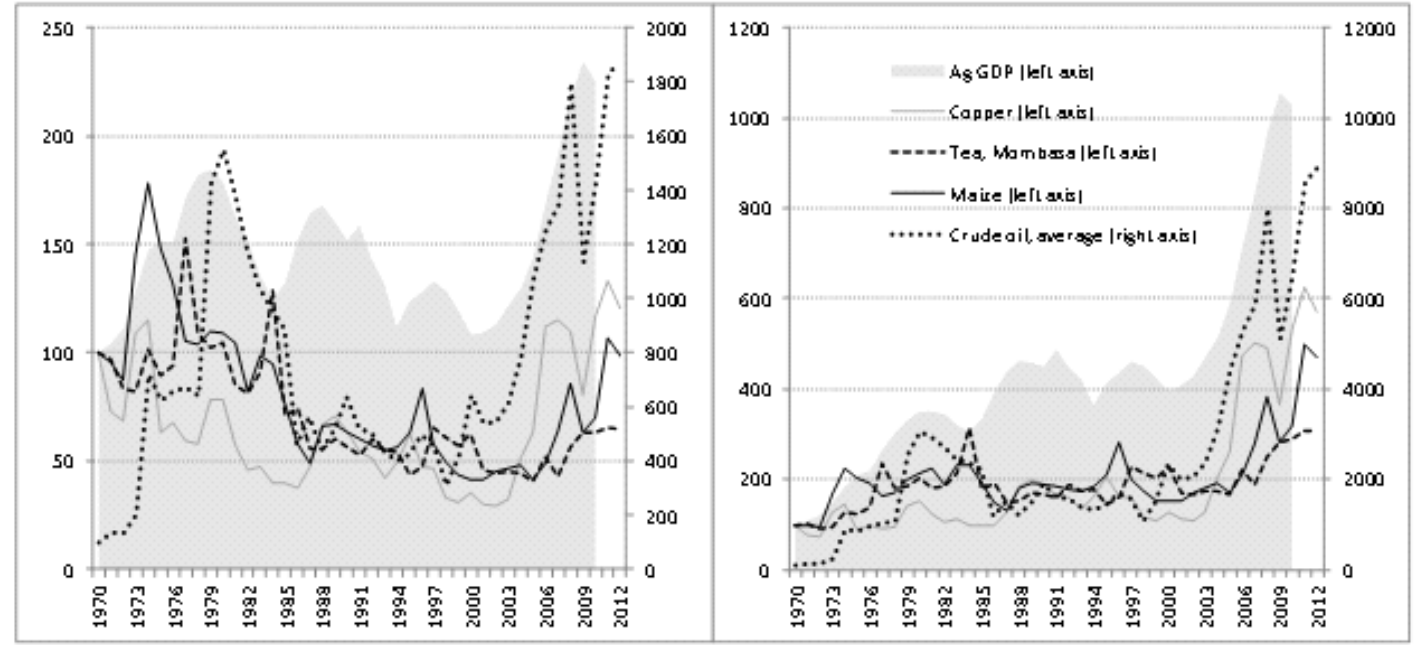

Source: Authors' calculations by normalizing to 100 for 1980. Price indexes based on World Bank (2011 and2012).

Note: Due to the high increase in crude oil prices over the same period, this is measured on the right axis.

AgGDP = agricultural gross domestic product.

Based on these simple observations of underlying trends, we ask a critical question: has the growth in agriculture value added been principally riding on the current commodity price boom, or have underlying changes in productivity (from increased investments and an enabling policy environment) been sufficiently large to explain a big part of the growth. The answer probably lies somewhere in between and is very much an empirical one.

The objective of this paper, therefore, is to analyze the structure of overall agricultural sector growth and performance in the most recent decade relative to past experience. We accomplish this by using growth-accounting and parametric methods, as presented in the next section, followed by two sections that review the results of analysis and offer explanations before concluding. We hope that the results from our empirical analysis not only enrich the academic debate over the recent recovery of agriculture in Africa but, more important, also inform future strategies for sustaining the growth momentum. This is especially timely as policymakers and development partners in SSA are demanding information to help guide future investment strategies and policy reforms in order to ensure growth, poverty reduction, and food security. ${ }^{1}$

\footnotetext{
${ }^{1}$ In 2003, African governments pledged to allocate at least 10 percent of their national budgets to agriculture, a goal that has since become a key goal of the African Union's Comprehensive Africa Agriculture Development Program (CAADP) of the New Partnership for Africa's Development (NEPAD). Since then, momentum for supporting agricultural growth as a development objective has been on the agenda of African governments and their development partners (see, for example, Badiane, Odjo, and Ulimwengu 2011).
} 


\section{METHODOLOGY}

To determine the composition of agricultural growth and factors explaining SSA's performance over time, we adopt both a growth-accounting and a parametric approach as described in Kohli (2002 and 2004) to decompose value-added growth into the contribution of each of the major factors determining growth: total factor productivity (TFP) change; change in the endowments of land, labor, and capital; movement in the terms of trade; and change in domestic output prices. Most growth-accounting methods are derived from Solow's original analysis (Solow 1957), but his approach appears inadequate for our purpose as it considers a single output, is not well suited to analyze open economies as it does not allow for imports and exports, and uses a restrictive Cobb-Douglas functional form. Kohli's (1991) method overcomes those constraints while allowing us to obtain parametric estimates of the growth decomposition into a secular and a shock component. As discussed in Kohli (2002), both approaches have a strong theoretical foundation: the parametric method based on the GDP function approach to modeling the production sector of an open economy (Kohli 1978 and 1991; Woodland 1982), whereas the nonparametric technique builds on work by Diewert and Morrison (1986), who examined the welfare effects of technological change and terms-of-trade shifts.

As the name entails, the GDP function approach uses a GDP function that assumes profit maximization and perfect competition, expressed as

$$
\pi=\pi\left(p_{t}, x_{t}, t\right) \equiv \max _{y_{t}}\left\{p_{t}^{\prime} y_{t}:\left(y_{t}, x_{t}\right) \in T_{t}\right\}
$$

where $T_{t}$ is the production possibility set at time $t$; the vector $x_{t} \equiv\left[x_{j t}\right], j \in\{L, K, L D\}$ represents factor endowments of labor, capital, and land; the output quantity vector is $y_{t} \equiv\left[y_{i t}\right], i \in\{C, I, M, X\}$ with output components including consumption goods $C$, investment goods $I$, exports $X$, and imports $M$ treated as a negative output. The corresponding input and output price vectors are $w_{t} \equiv\left[w_{j t}\right]$ and $p_{t} \equiv\left[p_{i t}\right]$. The technology is assumed to be convex, exhibiting constant returns to scale and free disposals. Factor endowments are treated as fixed, and prices of imports and outputs are considered as given.

Using the GDP function (1) and following Fox and Kohli (1997) we define the indexes that measure the four causes of GDP growth: (i) technological change; (ii) terms-of-trade change; (iii) change in factor endowments; and (iv) change in domestic prices. The index measuring TFP change between $t-1$ and $t$ is expressed as follows:

$$
T F P_{t, t-1} \equiv\left[\frac{\pi\left(p_{t-1}, x_{t-1}, t\right)}{\pi\left(p_{t-1}, x_{t-1}, t-1\right)} \frac{\pi\left(p_{t}, x_{t}, t\right)}{\pi\left(p_{t}, x_{t}, t-1\right)}\right]^{\frac{1}{2}}
$$

The index can be interpreted as the geometric mean of Laspeyres and Paasche productivity indexes respectively using $t-1$ and $t$ prices and quantities as reference. Similarly, the index capturing the GDP effect of a change in the terms of trade between $t-1$ and $t$ is defined as

$$
A_{t, t-1} \equiv\left[\frac{\pi\left(p_{M t}, p_{X t}, p_{N t-1}, x_{t-1}, t-1\right)}{\pi\left(p_{M t-1}, p_{X t-1}, p_{N t-1}, x_{t-1}, t-1\right)} \frac{\pi\left(p_{M t}, p_{X t}, p_{N t-1}, x_{t}, t\right)}{\pi\left(p_{M t-1}, p_{X t-1}, p_{N t}, x_{t}, t\right)}\right]^{\frac{1}{2}},
$$

where $P_{N}$ is the vector of domestic prices $p_{N} \equiv\left[p_{I}, p_{G}, p_{C}\right]^{\prime}$.

The contribution of factor $j$ to GDP growth between $t-1$ and $t$ is measured by the index

$$
X_{j t, t-1} \equiv\left[\frac{\pi\left(p_{t-1}, x_{j t}, x_{k t-1}, t-1\right)}{\pi\left(p_{t-1}, x_{j t-1}, x_{k t-1}, t-1\right)} \frac{\pi\left(p_{t}, x_{j t}, x_{k t}, t\right)}{\pi\left(p_{t}, x_{j t-1}, x_{k t}, t\right)}\right]^{\frac{1}{2}} .
$$


Finally, and in a similar fashion, the contribution to GDP growth of domestic prices between $t-1$ and $t$ is captured by

$$
P_{N t, t-1} \equiv\left[\frac{\pi\left(p_{M t-1}, p_{X t-1}, p_{N t}, x_{t-1}, t-1\right)}{\pi\left(p_{M t-1}, p_{X t-1}, p_{N t-1}, x_{t-1}, t-1\right)} \frac{\pi\left(p_{M t}, p_{X t}, p_{N t}, x_{t}, t\right)}{\pi\left(p_{M t}, p_{X t}, p_{N t-1}, x_{t}, t\right)}\right]^{\frac{1}{2}}
$$

\section{Growth-Accounting Approach}

For growth accounting, indexes (2) through (5) cannot be estimated directly as the GDP function $\pi(\cdot)$ is generally unknown. However, the approach followed by Kohli (2002) uses results from Diewert and Morrison (1986), who showed that as long as the GDP function has the translog form, an exact measure of indexes (2) through (5) can be derived from knowledge of the data alone. Table 2.1 shows the equivalent definition of these indexes if we assume the translog functional form for the GDP function.

Table 2.1-Definition of indexes for GDP decomposition when the GDP function is assumed to be of the translog functional form

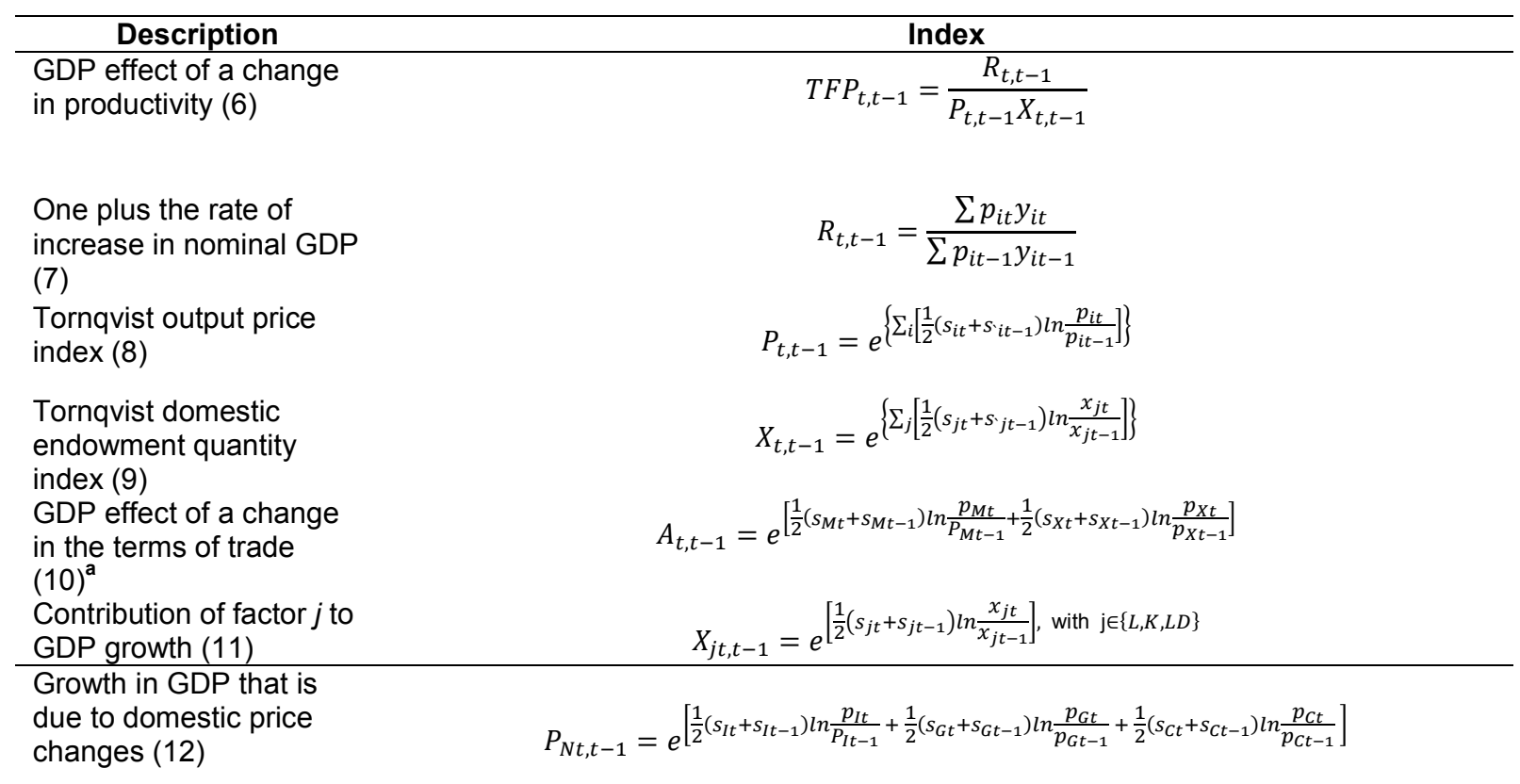

Source: Elaborated by authors

Notes: ${ }^{a}(10)$ is similar to a Tornqvist price index, except that the weights $s$ do not necessarily add up to 1. $\mathrm{GDP}=$ gross domestic product.

As shown by Kohli (1991), in the translog case (6), (9), (10), (11), and (12) give a complete decomposition of nominal GDP growth:

$$
R_{t, t-1}=T F P_{t, t-1} \cdot A_{t, t-1} \cdot X_{L t, t-1} \cdot X_{K t, t-1} \cdot X_{L D t, t-1} \cdot P_{N t, t-1} \cdot
$$

GDP growth is the result of changes in TFP, terms of trade, endowments of labor, capital, and land, and domestic prices. The productivity and the terms-of- trade indexes are defined for given prices of nontraded goods, and for given factor endowments; they measure the change in GDP that is attributable to technological progress and to the change in the terms of trade exclusively. The product of these two terms makes up what Diewert and Morrison (1986) called the welfare change index (Kohli 2002). The welfare 
change index times the factor indexes represent the change in real national income since domestic prices are still not included. Including price effects we get total GDP growth.

\section{Parametric Approach}

The parametric approach estimates a GDP function of the translog form, which, after omitting the time subscript, is expressed as

$$
\begin{aligned}
& \ln \pi=\alpha_{0}+\sum_{i} \alpha_{i} \ln p_{i}+\sum_{j} \beta_{j} \ln x_{j}+\frac{1}{2} \sum_{i} \sum_{h} \gamma_{i h} \ln p_{i} \ln p_{h}+\frac{1}{2} \sum_{j} \sum_{k} \phi_{j k} \ln x_{j} \ln x_{k} \\
& +\sum_{i} \sum_{j} \delta_{i j} \ln p_{i} \ln x_{j}+\sum_{i} \delta_{i t} \ln p_{i} t+\sum_{j} \phi_{j t} \ln x_{j} t+\beta_{t} t+\frac{1}{2} \phi_{t t} t^{2}, \\
& i, h \in\{C, I, G, M, X\}, j, k \in\{L, K, L D\},
\end{aligned}
$$

where $\sum_{i} \alpha_{i}=1, \sum_{j} \beta_{j}=1, \gamma_{i h}=\gamma_{h i}, \phi_{j k}=\phi_{k j}, \sum_{h} \gamma_{i h}=0, \sum_{k} \phi_{j k}=0, \sum_{j} \delta_{i j}=0, \sum_{i} \delta_{i j}=0$,

$\sum_{i} \delta_{i t}=0$, and $\sum_{j} \phi_{j t}=0$.

Assuming a perfectly competitive market, the output and input shares in GDP are

$$
\begin{gathered}
s_{i} \equiv p_{i} y_{i} / \pi=\alpha_{i}+\sum_{h} \gamma_{i h} \ln p_{h}+\sum_{j} \delta_{i j} \ln x_{j}+\delta_{i t} t, i \in\{C, I, G, M, X\}, \text { and } \\
s_{j} \equiv w_{j} x_{j} / \pi=\beta_{j}+\sum_{i} \delta_{i j} \ln p_{i}+\sum_{k} \phi_{j k} \ln x_{k}+\phi_{j t} t, j \in\{L, K, L D\} .
\end{gathered}
$$

The different indexes expressing changes in the GDP components presented above are expressed in parameters from the translog estimation.

The productivity index:

$$
S_{t, t-1}=\exp \left[\frac{1}{2} \sum_{i} \delta_{i t}\left(\ln p_{i t}+\ln p_{i, t-1}\right)+\frac{1}{2} \sum_{j} \phi_{j t}\left(\ln x_{j t}+\ln x_{j, t-1}\right)+\beta_{t}+\frac{1}{2} \phi_{t t}(2 t-1)\right]
$$

The terms of trade GDP adjustment index:

$$
\begin{aligned}
& A_{t, t-1}=\exp \left\{\frac{1}{2} \sum_{i} \sum_{h} \gamma_{i h}\left(\ln p_{i t} \ln p_{h t}-\ln p_{i, t-1} \ln p_{h, t-1}\right)\right. \\
& \left.+\sum_{i} \ln \left(\frac{p_{i t}}{p_{i, t-1}}\right)\left[\alpha_{i}+\frac{1}{2} \sum_{m} \gamma_{i m} \ln \left(p_{m t} p_{m, t-1}\right)+\frac{1}{2} \sum_{j} \delta_{i j} \ln \left(x_{j t} x_{j, t-1}\right)+\frac{1}{2} \delta_{i t}(2 t-1)\right]\right\} \\
& i, h \in\{M, X\}, m \in\{C, I, G\}, j \in\{L, K, L D\}
\end{aligned}
$$

The input quantity effects:

$$
\begin{aligned}
& X_{j t, t-1}=\exp \left\{\operatorname { l n } ( \frac { x _ { j t } } { x _ { j , t - 1 } } ) \left[\beta_{j}+\frac{1}{2} \sum_{k} \phi_{j k} \ln \left(x_{k t} x_{k, t-1}\right)+\frac{1}{2} \sum_{j} \delta_{i j} \ln \left(p_{i t} p_{i, t-1}\right)+\right.\right. \\
& \left.\left.+\frac{1}{2} \phi_{j t}(2 t-1)\right]\right\},+i, h \in\{M, X, C\} ; j \in\{L, K, L D\}
\end{aligned}
$$


The nontraded good price effect:

$$
\begin{aligned}
& P_{N t, t-1}=\exp \left\{\frac{1}{2} \sum_{i} \sum_{h} \gamma_{i h}\left(\ln p_{i t} \ln p_{h t}-\ln p_{i, t-1} \ln p_{h, t-1}\right)\right. \\
& \left.+\sum_{i} \ln \left(\frac{p_{i t}}{p_{i, t-1}}\right)\left[\alpha_{i}+\frac{1}{2} \sum_{m} \gamma_{i m} \ln \left(p_{m t} p_{m, t-1}\right)+\frac{1}{2} \sum_{j} \delta_{i j} \ln \left(x_{j t} x_{j, t-1}\right)+\frac{1}{2} \delta_{i t}(2 t-1)\right]\right\}, \\
& i, h \in\{C, I, G\}, m\{M, X\}, j \in\{L, K, L D\}
\end{aligned}
$$

The GDP decomposition using the parametric approach gives the potential or fitted value of GDP growth rather than the observed one, so the econometric equivalent to equation (13) in the accounting approach is as follows:

$$
\pi_{t, t-1}=S_{t, t-1} \cdot A_{t, t-1} \cdot X_{L t, t-1} \cdot X_{K t, t-1} \cdot X_{L D t, t-1} \cdot P_{N t, t-1},
$$

where all the terms on the right-hand side are calculated from the translog estimates as shown aboveequations (17) through (20). $S_{t, t-1}$ is defined by Fox and Kohli (1997) as the secular component of technological change, and the unexplained is calculated using $\mathrm{TFP}_{\mathrm{t}, \mathrm{t}-1}$ from equation (6) as

$$
U_{t, t-1} \equiv \frac{T F P_{t, t-1}}{\pi_{t, t-1}}
$$

As Fox and Kohli (1997) point out, this residual has been purged of trend shifts of the technology, so it can be considered as a measure of true productivity shocks. 


\section{RESULTS OF GROWTH DECOMPOSITION}

In the decomposition of agricultural gross domestic product (AgGDP) growth for 22 countries in SSA between 1980 and 2010 (see Table A.1 for a list of the countries), we use the methodologies described earlier in section 2. AgGDP values at current US\$ prices are from World Bank (2012). Export and import values from FAOSTAT in current US\$ are used to determine the share of exports, imports, and domestic absorption $(C+I+\mathrm{G})$ in total AgGDP. Export and import prices are indexes from FAOSTAT (2012), while AgGDP deflators are used as price indexes for each country. Factors used (capital stock, agricultural land, and labor) are also from FAOSTAT and are defined as follows:

- Capital stock in agriculture refers to a value that is attached to the total physical capital capacity available to produce agricultural goods in a particular year. These estimates were derived by the FAO Statistics Division using physical data on livestock, tractors, irrigated land, land under permanent crops, and so on, and the average prices for the year 1995. These data enabled the derivation of the capital stock in agriculture, which is the gross, and the annual change in the latter is taken to reflect investment in agriculture.

- Agricultural area includes (a) land under temporary agricultural crops, temporary meadows, and temporary fallow (less than five years); (b) permanent crops; and (c) permanent meadows and pastures.

- Economically active population in agriculture (agricultural labor force) is that part of the economically active population engaged in or seeking work in agriculture, hunting, fishing, or forestry.

Referring to the equations described in section 2, the translog agricultural GDP function in equation (14) and the derived input and output share equations (15) and (16) were estimated as a system of simultaneous equations using three-stage least squares. The resulting coefficients are summarized in Table A.2 in the Appendix.

Results of the AgGDP growth decomposition for 22 SSA countries and three periods are presented in Table 3.1. Results show that for the period analyzed, nominal AgGDP grew at an average annual rate of 3.7 percent. Between 1.3 and 1.7 percentage points of this growth is explained by increases in the use of land, labor, and capital; about 1.0 to 1.8 percentage points of total growth comes from TFP; terms of trade contribution was zero or negative; and the rest ( 0.6 to 1.4 percent) is explained by prices. 
Table 3.1-Decomposition of AgGDP using accounting and parametric methods

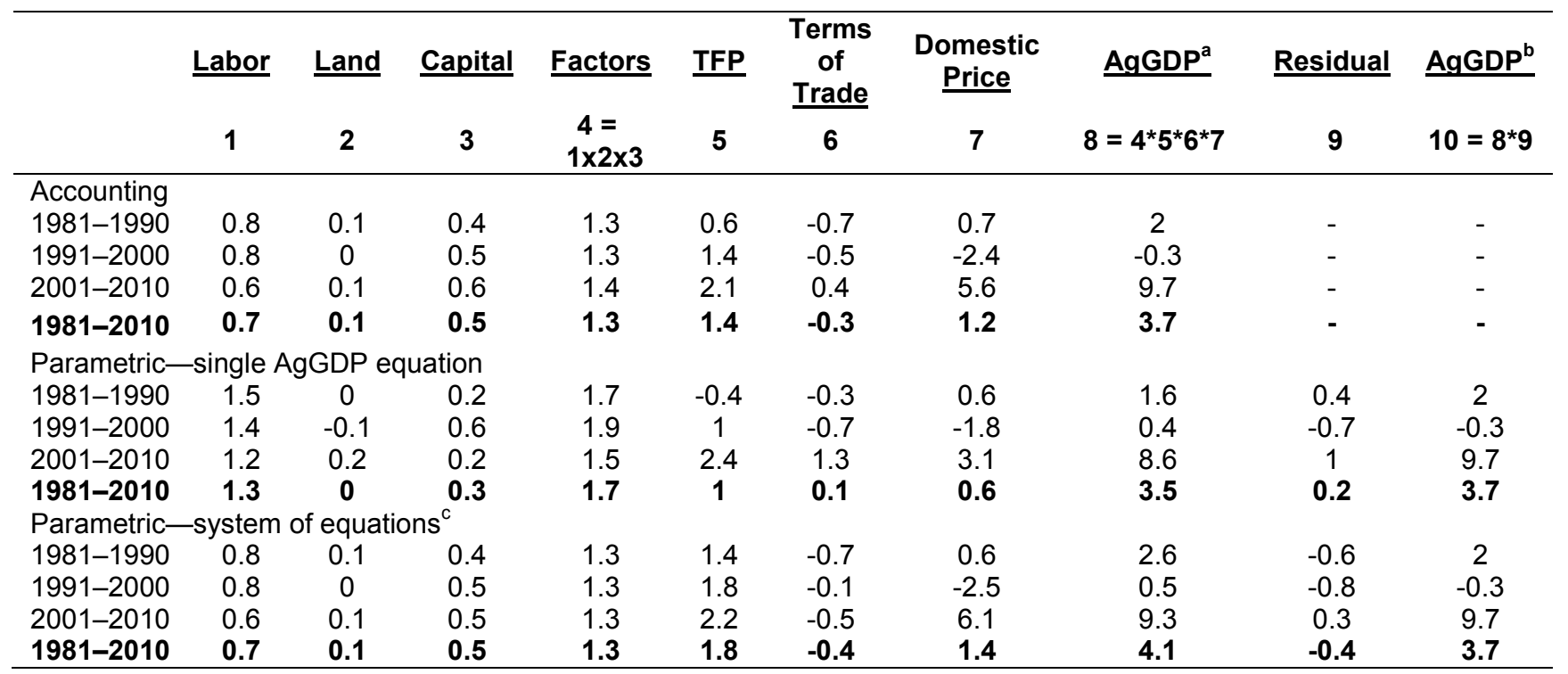

Source: Estimated by authors.

Note: These are simple averages for 22 SSA countries and converted to percentages.

${ }^{a}$ Total AgGDP (agricultural gross domestic product) growth with the accounting approach and AgGDP growth including only the secular component of TFP (total factor productivity) growth under the parametric approach.

${ }^{\mathrm{b}}$ AgGDP includes secular and shock components of productivity growth.

${ }^{c}$ AgGDP translog equation was estimated using a system of equations including three output and three input share equations.

To further analyze the results, we focus on the estimates obtained with the accounting approach. Table 3.2 shows that the drivers of AgGDP growth are different for the three periods. During the 1980s, a period of slow growth and the start of economic policy changes, agricultural growth was driven by changes in domestic prices and increasing labor use. TFP growth of only 0.6 percent contributes with 26 percent of total AgGDP growth during that period. In 2001-2010, almost two-thirds of AgGDP's 9.7 percent growth rate is explained by growth in domestic prices (real prices plus dollar inflation). The most important real contribution to AgGDP growth comes from TFP, growing at 2.15 percent and explaining 22.2 percent of AgGDP growth. Factors of production contribute only 15 percent of total growth, a small amount compared with their contribution in 1981-1990 (close to 66 percent).

Table 3.2-AgGDP growth decomposition

\begin{tabular}{|c|c|c|c|c|c|c|c|c|c|c|}
\hline & Labor & Capital & $\begin{array}{l}\text { Crop- } \\
\text { land }\end{array}$ & $\begin{array}{l}\text { Other } \\
\text { Land }\end{array}$ & $\begin{array}{c}\text { Terms of } \\
\text { Trade }\end{array}$ & TFP & $\begin{array}{c}\text { Total Real } \\
\text { Effect }\end{array}$ & $\begin{array}{l}\text { Real } \\
\text { Price }\end{array}$ & $\begin{array}{c}\text { Dollar } \\
\text { Inflation }\end{array}$ & $\begin{array}{l}\text { AgGDP } \\
\text { Growth }\end{array}$ \\
\hline \multicolumn{11}{|c|}{ Growth rate $^{\mathrm{a}}(\%)$} \\
\hline $1981-1990$ & 0.9 & 0.4 & 0.1 & 0.0 & -0.8 & 0.6 & 1.2 & -3.1 & 4.2 & -0.8 \\
\hline $1991-2000$ & 0.9 & 0.5 & 0.2 & -0.1 & 0.1 & 1.4 & 3.0 & -5.3 & 2.1 & 0.4 \\
\hline 2001-2010 & 0.7 & 0.7 & 0.2 & 0.0 & -0.2 & 2.2 & 3.6 & 3.9 & 2.3 & 11.5 \\
\hline \multicolumn{11}{|c|}{ Contribution to growth (\%) } \\
\hline 1981-1990 & 40.42 & 18.33 & 4.59 & 0.00 & -36.88 & 27.46 & 53.93 & -143.95 & 190.02 & 100.00 \\
\hline $1991-2000^{b}$ & -183.87 & -107.47 & -43.05 & 21.56 & -21.54 & -299.56 & -633.92 & 1175.21 & -441.29 & 100.00 \\
\hline $2001-2010$ & 7.01 & 7.23 & 2.07 & 0.00 & -2.08 & 22.57 & 36.81 & 39.42 & 23.78 & 100.00 \\
\hline
\end{tabular}

Source: Authors' estimation.

Notes: ${ }^{a}$ Decomposition is obtained for multiplicative indexes, so growth rates in percentage do not add up to exactly the same growth obtained with the index.

${ }^{\mathrm{b}}$ Growth in this period is negative, so, for instance, the contribution to negative growth of domestic price (which shows negative growth) is positive.

AgGDP = agricultural gross domestic product; TFP = total factor productivity. 
Results of the growth decomposition for the analyzed period reveal contrasting patterns of growth and shed some light on the drivers of growth in recent years. First, performance of agriculture production has been improving during the period as shown by average TFP growth rates, which have increased from 0.6 percent in the $1980 \mathrm{~s}$ to 1.4 percent in the 1990s and 2.2 percent in recent years. The decomposition of TFP growth into a secular component and a shock component obtained from the econometric analysis helps us to see this evolution (Figure 3.1). During the 1980s, agricultural TFP showed a low secular growth rate that was subject to large negative shocks. During the early 1990s, faster growth of secular TFP was still affected by large negative shocks. In recent years, TFP growth rates achieved their highest levels, whereas TFP shocks are smaller and fluctuate around zero values.

Figure 3.1—Secular and shock components of TFP growth (22 SSA countries)

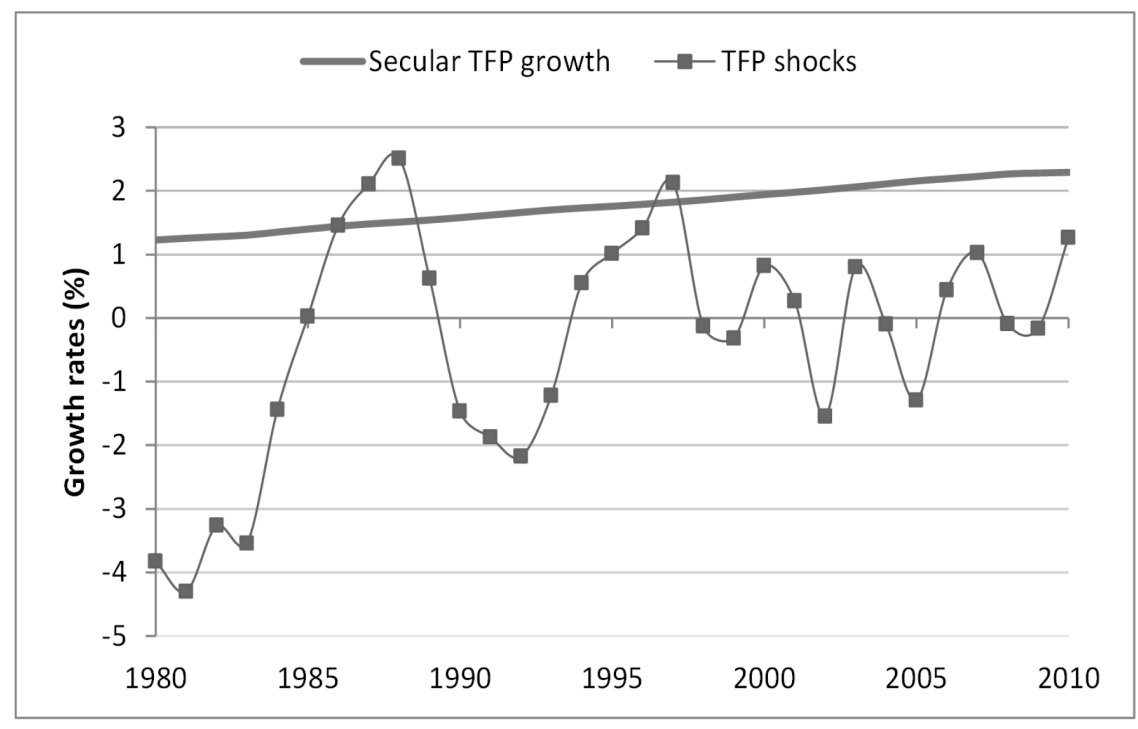

Source: Authors' estimation.

Note: $\quad$ TFP $=$ total factor productivity; SSA = Africa south of the Sahara.

One possible interpretation of these results is that changes in the economic environment have reduced the incidence of negative shocks in SSA's TFP growth while favoring an increase in the secular TFP growth. However, these results should be taken with caution as secular growth in TFP appears to be slowing down by the end of the period and observed trends cannot be projected to the future without a better understanding of the drivers of TFP growth.

A second aspect to notice from our results is that average growth in real terms (growth that does not come from price increases) is 3.5 percent for the last 10 years, 0.5 percent above real growth in 19912000 and well above growth in the 1980s when real AgGDP growth grew only at 1.25 percent. The difference in real growth between periods is the result of higher growth in TFP as factor growth was very similar for the three periods (1.5 percent approximately). The trends and growth patterns of the different factors explaining AgGDP growth in SSA are presented in Figure 3.2.

The indexes in the figure represent the levels of TFP, factors of production, terms of trade, and price relative to their respective levels in 1994. The figure shows that growth in the use of land, labor, and capital has been constant and does not appear to have been affected by economic fluctuations during the period. Similarly, terms of trade for agriculture did not change significantly during the period and have been historically negative for SSA. This leaves us with TFP and domestic prices as the two main factors driving AgGDP growth. According to our results, SSA's improved performance started in 1994. After that year TFP shows a clear increasing trend with little fluctuations until the present. On the other hand, domestic prices fluctuated within a band of 30 percentage points between 1980 and 2005, with low peaks in 1984, 1994, and 2002, taking off after 2005. 
Figure 3.2 - Evolution of different factors contributing to AgGDP growth in SSA, 1980-2010 $(1994=1)$

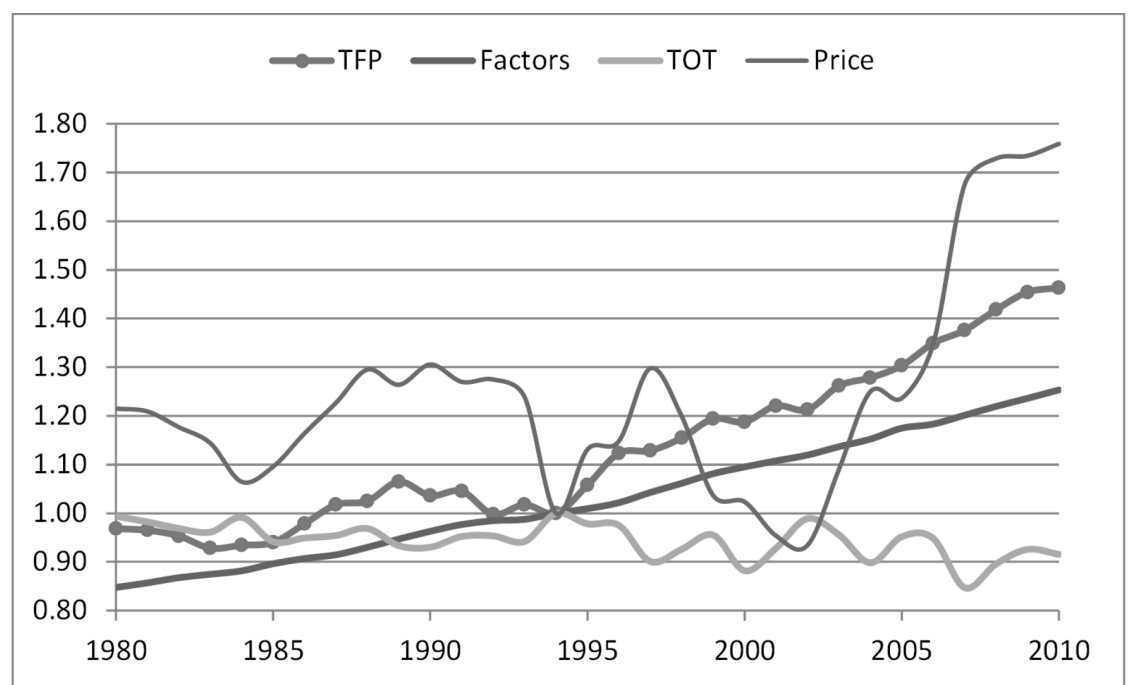

Source: Authors' estimation.

Notes: Values are simple averages of indexes for 22 countries: Angola, Botswana, Cameroon, Chad, DRC, Côte d'Ivoire, Ethiopia, Ghana, Guinea, Kenya, Madagascar, Malawi, Mali, Mozambique, Namibia, Nigeria, Rwanda, Senegal, Sudan, Tanzania, Uganda, and Zambia.

AgGDP = agricultural gross domestic product; SSA = Africa south of the Sahara; TFP = total factor productivity; TOT $=$ terms of trade.

The better performance of agriculture in recent years has extended to almost all SSA countries, which is good news, but also evidence that the region has benefited from common regional (economic, political, and so on) and external factors that explain in part the observed growth. Table 3.3 presents the decomposition of AgGDP growth for SSA countries sorted into three groups: top performers, bottom performers, and average performers. The major difference in performance between the top and bottom groups is, not surprisingly, prices and TFP. Higher prices explain about 45 percent of the difference in AgGDP growth between top and bottom performers, while TFP explains another 35 percent. Prices are even more important in explaining the AgGDP growth differential between the average and bottom groups. Prices explain about 80 percent of that differential while TFP explains the remaining 20 percent. 
Table 3.3-AgGDP growth decomposition and growth performance of SSA countries, 2001-2010 (\%)

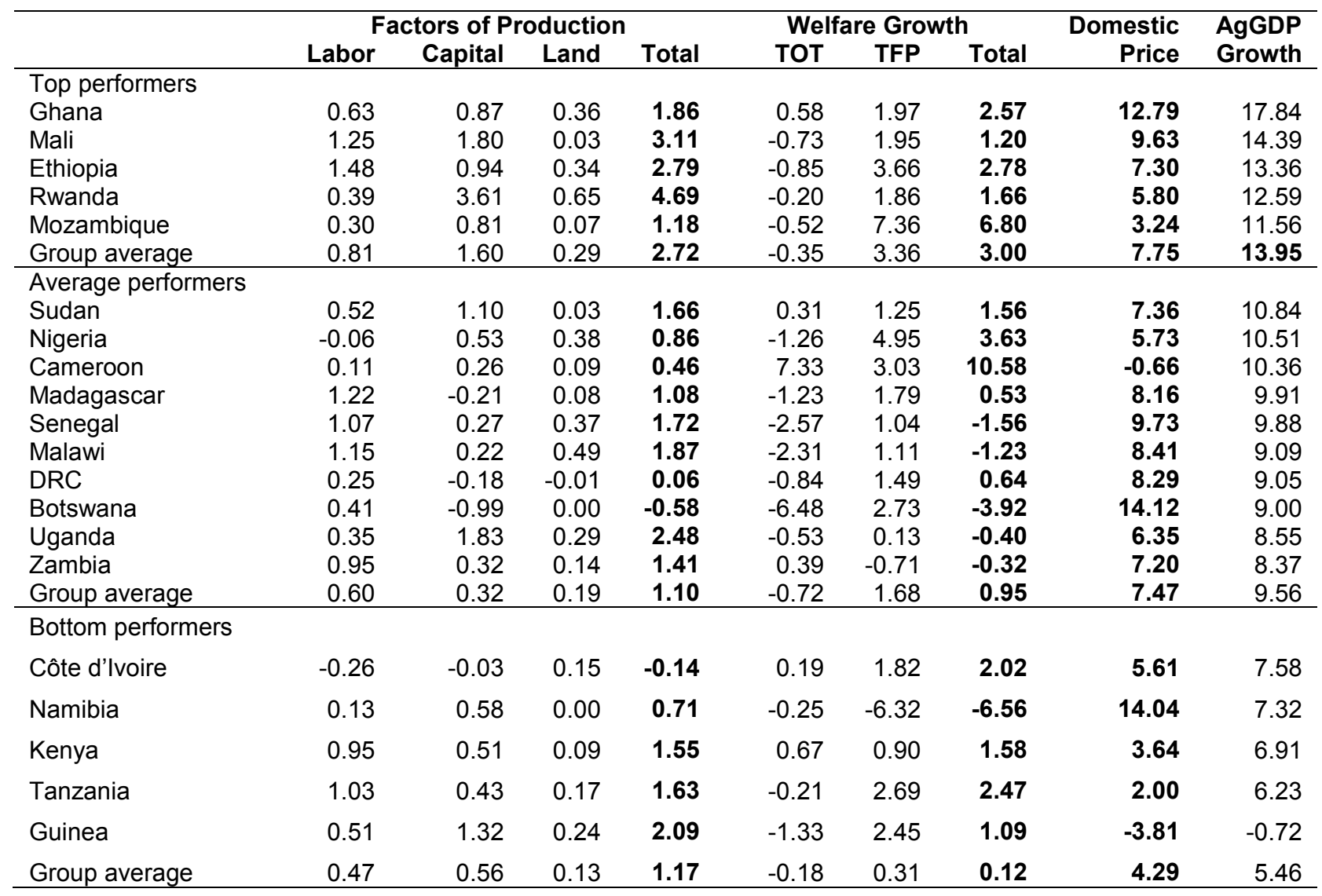

Source: Authors' estimation.

Notes: AgGDP = agricultural gross domestic product; $\mathrm{SSA}=$ Africa south of the Sahara; TOT $=$ terms of trade; TFP $=$ total factor productivity.

Table 3.4 shows a different perspective on performance of agriculture by classifying countries according to growth in TFP and terms of trade, the welfare-enhancing components of GDP. There is a clear differentiation now between top performers and the rest. TFP growth is 4 percent on average in the top-performing group, 1.5 in the average group, and negative in the bottom group. Overall AgGDP growth is still highest in the top group (12.7 percent versus 8.5 percent and 8.8 percent in the other groups), but bottom performers now show the highest growth in prices. 
Table 3.4-AgGDP growth decomposition and TFP and TOT growth performance of SSA countries, 2001-2010 (\%)

\begin{tabular}{|c|c|c|c|c|c|c|c|c|c|}
\hline & \multicolumn{4}{|c|}{ Factors of Production } & \multicolumn{3}{|c|}{ Welfare Change } & $\begin{array}{r}\text { Domestic } \\
\text { Price }\end{array}$ & $\begin{array}{l}\text { AgGDP } \\
\text { Growth }\end{array}$ \\
\hline Top performers & & & & & & & & & \\
\hline Cameroon & 0.11 & 0.26 & 0.09 & 0.46 & 7.33 & 3.03 & 10.58 & -0.66 & 10.36 \\
\hline Mozambique & 0.30 & 0.81 & 0.07 & 1.18 & -0.52 & 7.36 & 6.80 & 3.24 & 11.56 \\
\hline Nigeria & -0.06 & 0.53 & 0.38 & 0.86 & -1.26 & 4.95 & 3.63 & 5.73 & 10.51 \\
\hline Ethiopia & 1.48 & 0.94 & 0.34 & 2.79 & -0.85 & 3.66 & 2.78 & 7.30 & 13.36 \\
\hline Ghana & 0.63 & 0.87 & 0.36 & 1.86 & 0.58 & 1.97 & 2.57 & 12.79 & 17.84 \\
\hline Group average & 0.49 & 0.68 & 0.25 & 1.43 & 1.06 & 4.19 & 5.27 & 5.68 & 12.72 \\
\hline \multicolumn{10}{|c|}{ Average performers } \\
\hline Tanzania & 1.03 & 0.43 & 0.17 & 1.63 & -0.21 & 2.69 & 2.47 & 2.00 & 6.23 \\
\hline Côte d'Ivoire & -0.26 & -0.03 & 0.15 & -0.14 & 0.19 & 1.82 & 2.02 & 5.61 & 7.58 \\
\hline Rwanda & 0.39 & 3.61 & 0.65 & 4.69 & -0.20 & 1.86 & 1.66 & 5.80 & 12.59 \\
\hline Kenya & 0.95 & 0.51 & 0.09 & 1.55 & 0.67 & 0.90 & 1.58 & 3.64 & 6.91 \\
\hline Sudan & 0.52 & 1.10 & 0.03 & 1.66 & 0.31 & 1.25 & 1.56 & 7.36 & 10.84 \\
\hline Mali & 1.25 & 1.80 & 0.03 & 3.11 & -0.73 & 1.95 & 1.20 & 9.63 & 14.39 \\
\hline Guinea & 0.51 & 1.32 & 0.24 & 2.09 & -1.33 & 2.45 & 1.09 & -3.81 & -0.72 \\
\hline DRC & 0.25 & -0.18 & -0.01 & 0.06 & -0.84 & 1.49 & 0.64 & 8.29 & 9.05 \\
\hline Madagascar & 1.22 & -0.21 & 0.08 & 1.08 & -1.23 & 1.79 & 0.53 & 8.16 & 9.91 \\
\hline Zambia & 0.95 & 0.32 & 0.14 & 1.41 & 0.39 & -0.71 & -0.32 & 7.20 & 8.37 \\
\hline Group average & 0.68 & 0.87 & 0.16 & 1.71 & -0.30 & 1.55 & 1.24 & 5.39 & 8.51 \\
\hline \multicolumn{10}{|c|}{ Bottom performers } \\
\hline Uganda & 0.35 & 1.83 & 0.29 & 2.48 & -0.53 & 0.13 & -0.40 & 6.35 & 8.55 \\
\hline Malawi & 1.15 & 0.22 & 0.49 & 1.87 & -2.31 & 1.11 & -1.23 & 8.41 & 9.09 \\
\hline Senegal & 1.07 & 0.27 & 0.37 & 1.72 & -2.57 & 1.04 & -1.56 & 9.73 & 9.88 \\
\hline Botswana & 0.41 & -0.99 & 0.00 & -0.58 & -6.48 & 2.73 & -3.92 & 14.12 & 9.00 \\
\hline Namibia & 0.13 & 0.58 & 0.00 & 0.71 & -0.25 & -6.32 & -6.56 & 14.04 & 7.32 \\
\hline Group average & 0.62 & 0.38 & 0.23 & 1.24 & -2.43 & -0.26 & -2.73 & 10.53 & 8.77 \\
\hline
\end{tabular}

Source: Authors' estimation.

Notes: $\mathrm{AgGDP}=$ agricultural gross domestic product; $\mathrm{TOT}=$ terms of trade; $\mathrm{TFP}=$ total factor productivity; $\mathrm{SSA}=\mathrm{Africa}$ south of the Sahara.

In sum, results from the growth decomposition analysis show bad and good news for SSA's agriculture. The bad news is that two-thirds of agricultural growth in recent years is the result of growth in domestic prices, which could be hiding very different situations in terms of performance based on TFP growth. Claims of a booming African agriculture based on the two-digit AgGDP growth rates shown by the region in the past 10 years are misleading, and more analysis is needed to get a better understanding of future prospects. The good news, on the other hand, is the evidence of recovery and sustained TFP growth in agriculture, as the figures for TFP growth show. There could certainly be measurement errors and problems with data quality that might question the actual levels of TFP growth rates obtained in the analysis. Our focus here is not to determine the absolute value of TFP growth rates but to shed light on the evolution of agriculture's performance in SSA. With these considerations, the conclusion obtained from our results is that there is a clear change in the region's agricultural performance. However, questions remain about the factors behind that productivity growth and its sustainability in the future. We discuss this in the next section. 


\section{EXPLAINING THE DRIVERS OF GROWTH}

In previous sections we showed evidence of SSA agriculture's recovery after the lost years in the 1980s and 1990s. Other studies have shown evidence that this recovery is related at least in part to policy changes that reduced the burden previous policies had put on agriculture, but that is not the whole story, as different factors with very different implications for future growth could be driving agricultural TFP growth. The ideal situation, the one that could generate the best prospects for agriculture's future growth, would be one in which present TFP growth is mainly explained by technical change. In such a situation, we would observe adoption of new technologies along with one or more of the following: greater use of chemical inputs; increased yields; labor productivity. We expect such a process to be related also to increasing commercialization of agricultural production.

On the other hand, there may be other explanations for TFP growth that are not necessarily related to the process of technical change and the incorporation of new technologies. The other component of TFP growth apart from technical change is growth in technical efficiency. Growth driven by technical efficiency changes could result from producers increasing output using the same technology and resources they used in the past by better allocating and managing those resources in the production process. At the country level, efficiency gains could be the result of policy changes that, for instance, give incentives to producers to change resource allocation, increasing the area planted with some crops and reducing production of others, or changing the relative intensity in the use of inputs. This is plausible given the poor performance of SSA agriculture in the past. In what follows, we look at some of the evidence available to see which of the TFP growth stories is the most likely for SSA.

We first look at the evolution of variables that are related to technical change and adoption of new technologies, such as the use of fertilizer and growth in partial factor productivity measures like yield and labor productivity, and also to the evolution of public research and development (R\&D) investment in SSA. We then focus on two major pieces of evidence for the alternative story of efficiency growth. The first piece of evidence is the importance of changes in the structure of production explaining output growth after policy reforms and changes in the importance of international and domestic markets for agricultural products. In other words, how much of total growth is explained by changes in land use and relative growth of different activities rather than by productivity growth within activities? For the second piece of evidence, we look at the correlation between growth performance during 1970-1983, the period before reforms, and growth performance in the recent period of high agricultural growth. A negative correlation between growth in recent years and growth in 1981-1995 would be evidence of catching up to production levels of the 1980s and 1990s. In other words, the worse a country performs in agricultural production before 1994, the better the country's performance should be in the $2000 \mathrm{~s}$.

\section{Technical Change and TFP Growth}

\section{Investment in Agricultural R\&D}

Increasing the stock of knowledge is widely acknowledged as one strategy for enhancing productivity growth, and investment in R\&D is the avenue through which to increase the stock of knowledge in agriculture. Weiser (2005), who surveyed the literature on the impact of R\&D investment on productivity, asserts that $R \& D$ has a large and significant impact on firm performance, although the estimated returns vary considerably, from an average of 29 percent, to a lower bound of 7 percent, and to an upper bound of 69 percent. Similar results were found for agriculture by Griliches (1992), Mullen (2007), Mullen and Cox $(1995,1996)$, and Alston et al. (2000). For instance, the meta-analysis of rates of return to agricultural R\&D by Alston et al. (2000) shows that the returns from 1,886 estimates found in 292 studies averaged 100 percent per year for research, 85 percent for extension, 48 percent for studies that estimated the returns to research and extension jointly, and 81 percent for all the studies combined. The median rates were 48.0 percent for research, 62.9 percent for extension, 37.0 percent for joint research and extension, and 44.3 percent across all studies. 
Given this evidence, the question is this: what happened with SSA's agricultural R\&D investment in recent years? Is it possible to relate recent TFP growth to increased investment in agricultural R\&D? We briefly discuss here the evidence on the two determinants of agricultural R\&D on TFP growth: the R\&D-output elasticity for SSA and the evolution of R\&D investment in the region.

The first consideration to be made is that substantial lags exist between the time expenditures on $\mathrm{R} \& \mathrm{D}$ occur and the time they affect productivity. There is a vast literature on this issue, but we focus on evidence for SSA. Block (1995) finds that agricultural research expenditures, lagged by 10 years, were significant in explaining the recovery of African agricultural productivity during the 1980s. This result is consistent with a study by Alene (2010), who finds that the maximum effect of agricultural R\&D occurs with a lag of about 10 years.

With respect to R\&D-output elasticities, Nin Pratt and Fan (2009) conducted a literature review looking for evidence of elasticity values for different developing regions and found only three studies estimating R\&D elasticities for Africa. Lusigi and Thirtle (1997) estimated the elasticity of TFP growth with respect to R\&D expenditure for 47 African countries for the period 1961-1991 and determined an elasticity value of 0.031 . Thirtle, Hadley, and Townsend (1995), working with data for 22 African countries for 1971-1986, estimated an elasticity of output with respect to R\&D expenditures of 0.015 .

More recently, Alene and Coulibaly (2009) estimated a much higher elasticity of productivity with respect to agricultural research (0.38) for the period 1980-2003 for 27 SSA countries. Block (2010) finds that econometric estimates of a production function that includes a 10-year lag of log agricultural $R \& D$ expenditures (net of input quality adjustments) results in a production elasticity of approximately $0.2(\mathrm{P}=0.000)$, meaning that doubling the level of agricultural $\mathrm{R} \& \mathrm{D}$ expenditures at time $t$ would boost agricultural output per worker by 20 percent at time $t+10$.

Fuglie and Rada (2011) also find a significant relationship between R\&D investment and agricultural TFP growth in SSA, although their estimates of research-to-TFP elasticities are lower than those in Block (2010) and Alene (2010) and more in line with those found in the literature of the 1990s. According to Fuglie and Rada, national agricultural research has a significant, direct effect on productivity and facilitates the uptake of new technologies emanating from the CGIAR centers. Through these two pathways, national agricultural research has an output elasticity of 0.039 . About 90 percent of the effect of national $R \& D$ on production is a direct effect, and the remaining 10 percent is due to national research collaboration with CGIAR. Analyzing the impact of different policy indicators together with the effect of agricultural R\&D investment, Yu and Nin Pratt (2011) obtained a nonsignificant impact of agricultural R\&D investment on TFP, but a significant response of agricultural TFP to money supply, inflation, sectoral support, and trade openness. Finally, Nin Pratt (2011) obtains a significant TFP-R\&D elasticity estimate of 0.014 for a sample of 19 countries for 1981-2010.

Evidence shows that the highest values for agriculture R\&D elasticities among developing regions are found in Asia and in particular in China with estimated values around 0.2, which appear to be the most robust estimates from the literature (Nin Pratt and Fan 2009). Based on this evidence we conclude that the most likely values for SSA's TFP-R\&D elasticity are in the range of $0.015-0.040$ as estimated in the literature of the 1990s and in some of the recent studies, as we expect this elasticity to be below Asian values. Assuming that the maximum effect of R\&D investment is observed with a 10-year lag, and that the TFP-R\&D elasticity falls in a range going from the most likely value of 0.03 to an optimistic maximum of 0.2 , we look at the evolution of R\&D in SSA in the past 20 years to see how it might have contributed to agricultural growth in recent years.

Figure 4.1 presents the evolution of total agricultural R\&D for 25 SSA countries during 1981$2008 .^{2}$ It is clear from the figure that SSA reduced agricultural R\&D investment in real US dollars during the 1980s and 1990s. Even in purchasing power parity (PPP) international dollars, Nigeria experienced a sharp decline in $R \& D$ expenditure while other countries saw expenditure stagnate. The recovery in R\&D expenditure comes only by the end of the 1990 s and early 2000s. Table 4.1 shows that Nigeria resumed

\footnotetext{
${ }^{2}$ We would like to thank Kathleen Flaherty, data analysis specialist for the Agricultural Science and Technology Indicators (ASTI) initiative, who kindly provided the latest available data on agricultural R\&D investment in SSA.
} 
growth in R\&D investment after 1995 at average rates of 10 to 12 percent measured in PPP international dollars, reaching investment levels of the early 1980s only by the end of the period. R\&D investment in other countries started growing only in the 2000 s at average rates of 2.75 percent in PPP international dollars.

Figure 4.1—Trends in total public agricultural R\&D spending, 1981-2008

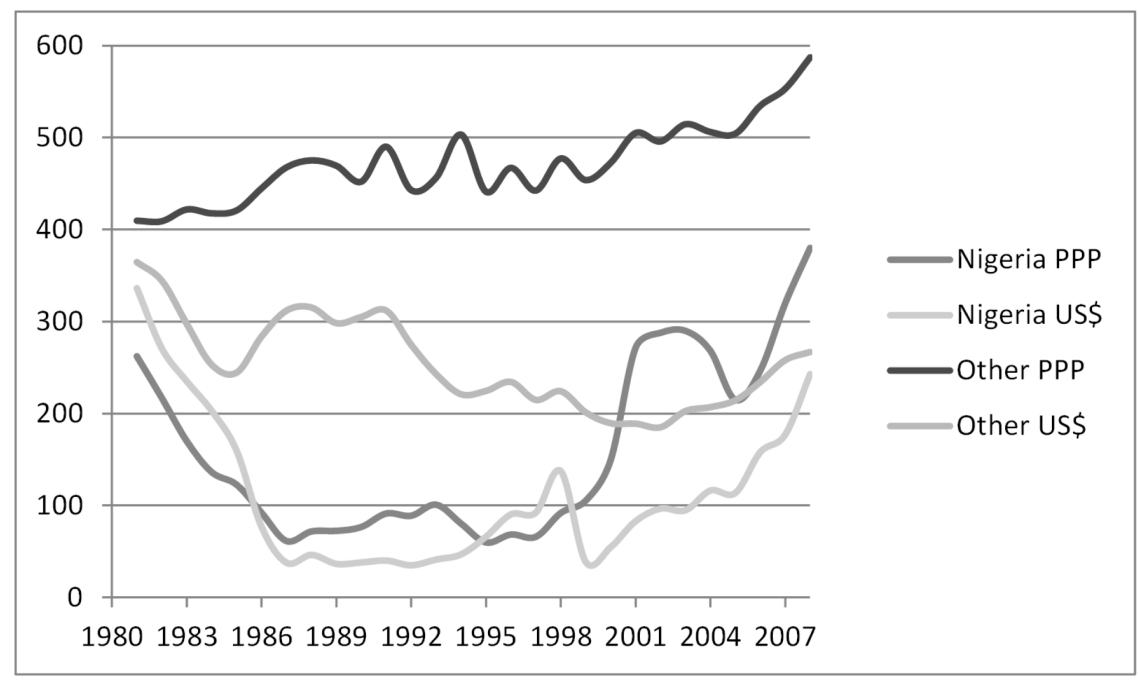

Source: Authors using data from ASTI (2011).

Notes: This includes Nigeria and 24 other SSA countries.

$\mathrm{R} \& \mathrm{D}=$ research and development; $\mathrm{PPP}=$ purchasing power parity.

Table 4.1-Average growth rates of total public agricultural $R \& D$ spending for different periods

\begin{tabular}{lrrr}
\hline & $\mathbf{1 9 8 1 - 1 9 9 4}$ & $\mathbf{1 9 9 5 - 2 0 0 0}$ & $\mathbf{2 0 0 1 - 2 0 0 8}$ \\
\hline Nigeria (R\&D in PPP I\$) & -8.10 & 10.89 & 12.38 \\
Nigeria (R\&D in 2005 US\$) & -13.14 & 2.61 & 20.50 \\
Other (R\&D in PPP I\$) & 1.48 & -1.05 & 2.75 \\
Other (R\&D in 2005 US\$) & -3.51 & -2.53 & 4.38 \\
\hline
\end{tabular}

Source: Authors' calculation.

Notes: This is for Nigeria and 24 other SSA countries.

$\mathrm{R} \& \mathrm{D}=$ research and development PPP I = purchasing power parity international.

Applying an output-R\&D elasticity range for SSA going from 0.03 to 0.2 as discussed above, we calculate the expected range of agricultural growth in 2001-2010 due to R\&D investment. The results are presented in Figure 4.2 
Figure 4.2-Cumulative agricultural growth between 2000 and 2010 due to $R \& D$ investment

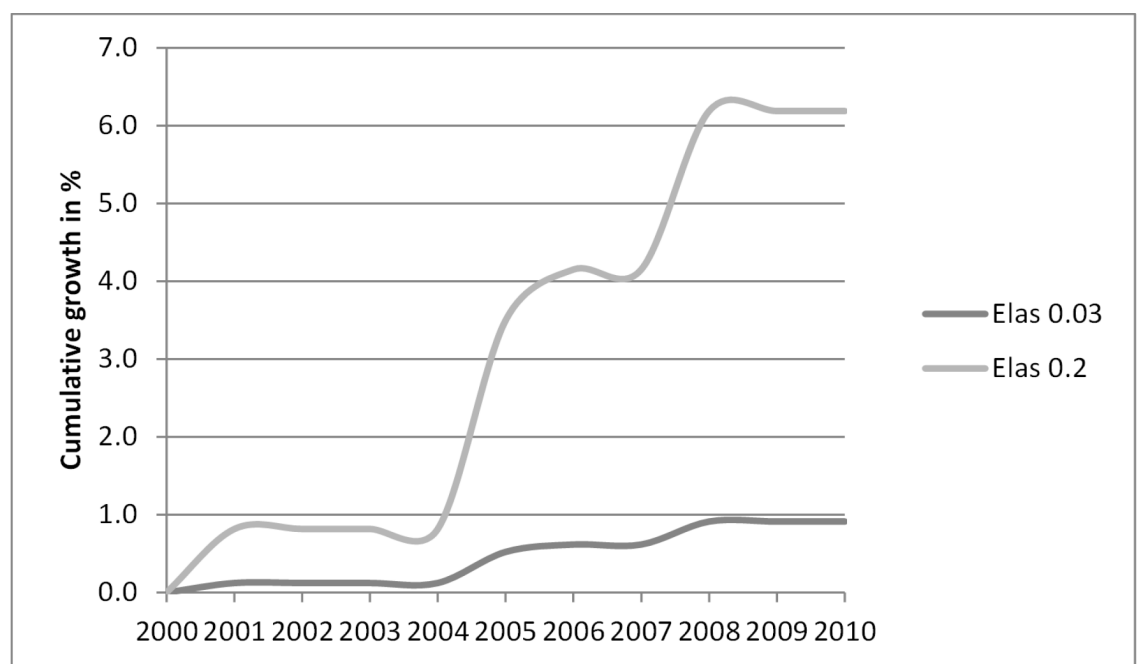

Source: Authors' calculation using data from ASTI (2011).

Note: This is for $25 \mathrm{SSA}$ (Africa south of the Sahara) countries assuming a 10-year lag of the effect of investment on output and output-R\&D (research and development) elasticities of 0.03 and 0.2 .

Given stagnated or even negative R\&D expenditure growth during the first half of the 1990s, we do not expect a significant impact of R\&D investment on agricultural growth in the first half of the 2000s. We expect $R \& D$ investment to have contributed less than 1 percentage point to total agricultural growth in the five-year period from 2000 to 2004 . With the most likely output-R\&D elasticity for SSA countries of 0.03 , total agricultural growth resulting from R\&D investment would be of only 1 percent for the whole period or of 0.11 percent annually. With the most overly optimistic elasticity of 0.2 , total estimated growth between 2000 and 2010 is 6 percent or 0.6 percent annually.

A recent study by Beintema and Stads (2011) goes beyond the quantitative evidence we present here. They refer to the 1990s as a decade of stagnation for R\&D investment in SSA, followed by a period of accelerated growth from 2001 to 2008 during which investment in public agricultural R\&D averaged more than 20 percent growth. However, according to Beintema and Stads, that growth occurred only in a few countries mostly as the result of government commitments to augment low salary levels and to rehabilitate available infrastructure after years of underinvestment. Despite that growth in R\&D investment, the average qualification level of research staff has continued to deteriorate (Beintema and Stads 2011). Given this evidence and past trends in public agricultural R\&D expenditure, and in particular given low and decreasing investment during most of the 1990s, we conclude that R\&D investment could not have played a significant role in SSA's 2000-2010 TFP growth.

\section{Fertilizer Use}

It is well known that fertilizer use in SSA (for example, kilograms (kgs) of fertilizer per hectare (ha)) is the lowest in the world (see, for example, Lipton 2012). Available data show that fertilizer use in the past 10 years is still very low and has been growing modestly, which makes it an unlikely candidate to explain increased growth in AgGDP and TFP. Figure 4.3 shows the evolution of the average use of fertilizer per hectare in SSA and compares it with fertilizer use in South Asia. 
Figure 4.3-Comparative evolution of fertilizer use in SSA and South Asia (kilograms per hectare of cropland)

(a) Trends

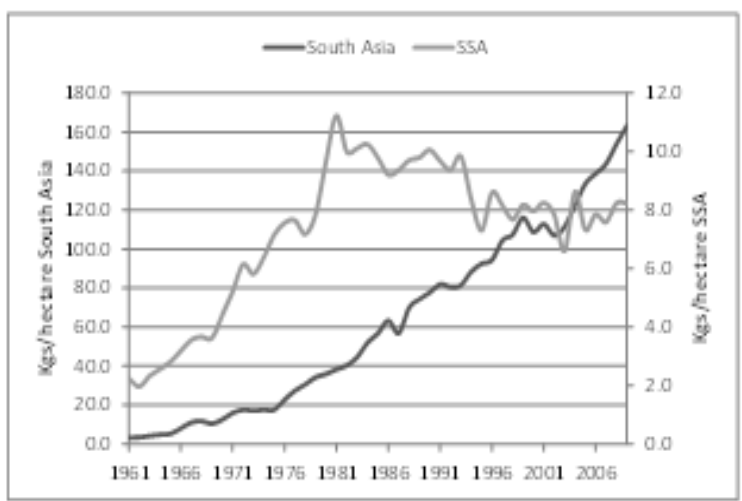

Source: Authors using data from FAOSTAT (2012). (b) Growth rates

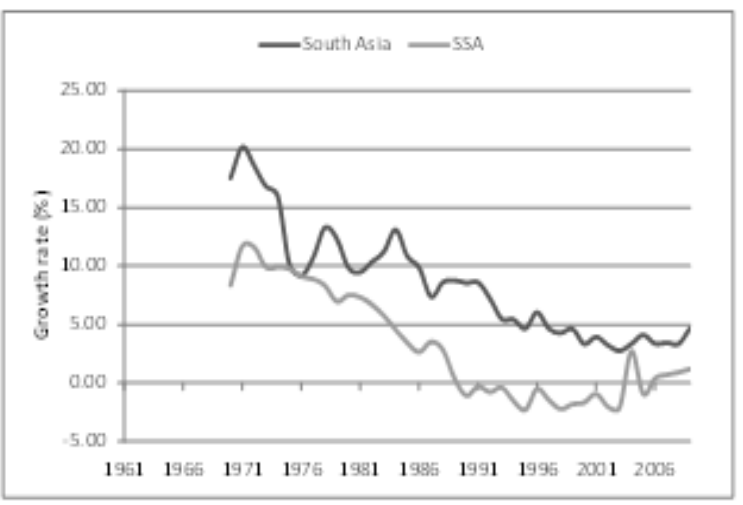

Note: SSA = Africa south of the Sahara.

Fertilizer use in South Asia in the early 1960s was only $3 \mathrm{kgs} /$ hectare compared with about 2 $\mathrm{kgs} /$ hectare in SSA. Although fertilizer use increased in the 1960s and 1970s in both regions, growth rates in South Asia were twice as high as those in SSA in the same period. Early Green Revolution growth rates of fertilizer use in South Asia were 20 percent per year and oscillated between 10 percent and 15 percent until the late 1980s. The use of fertilizer in SSA increased historically from $2 \mathrm{kgs}$ per hectare in the early 1960s to about $11 \mathrm{kgs}$ in 1980. It is likely that as a consequence of policy changes and the high costs of some of the fertilizer subsidy programs being implemented in some countries, the recovery of agriculture performance coincides with an actual reduction in the use of fertilizer. There seems to be an inflection point in the declining trend in recent years, although the countries in our sample are still below the levels of fertilizer per hectare used in the 1990s. Growth in fertilizer use per hectare between 1994 and 2005 is negative and close to zero. Average annual growth after 2005 for our sample of countries becomes a positive 1.6 percent.

Figure 4.4 compares the evolution of fertilizer use per hectare for countries grouped according to their performance in TFP growth. The pattern shown by the different countries is similar to that of the average of all countries with some particular characteristics that is worth noticing. The best performers are using the lowest fertilizer doses and also growing the least in the use of fertilizer. The bottom performers show the fastest growth in fertilizer use in recent years. We conclude that increased use of fertilizer does not appear to be the main suspect to explain improved performance of agriculture in SSA. 
Figure 4.4-Evolution of the use of fertilizer in countries classified according to their TFP growth performance in 1995-2010 (kilograms per hectare)

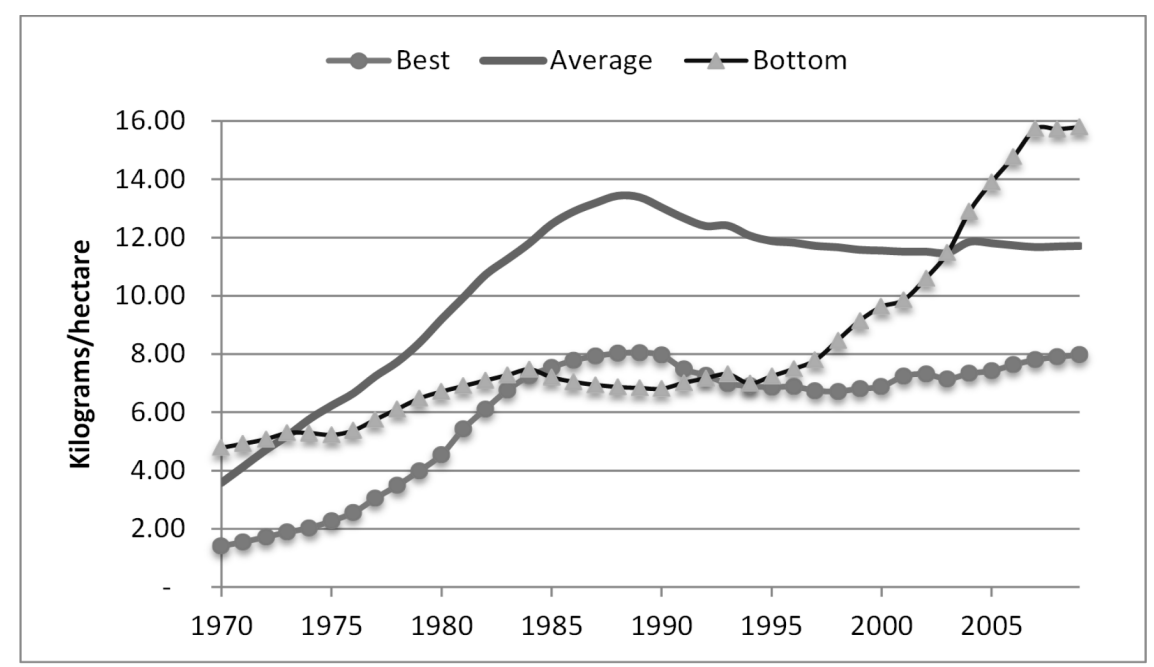

Source: Elaborated by authors using data from FAOSTAT (2012).

Note: $\quad$ TFP $=$ total factor productivity.

\section{Land and Labor Productivity}

We expect low fertilizer use to be related to relatively low levels of output per hectare. Crop yields in SSA have remained at low levels, showing low growth and contributing little to overall output growth. Figure 4.5 clearly shows that since 1985, output growth has been driven by increased crop area rather than by yields. It is only after the end of the 1990s that land productivity started contributing again to output growth, although growth rates of output per hectare are low (between 1 percent and 1.5 percent, Figure $4.5[\mathrm{~b}])$.

Figure 4.5-Evolution of output per hectare, output, and crop area in SSA, 1970-2009

(a) Trends

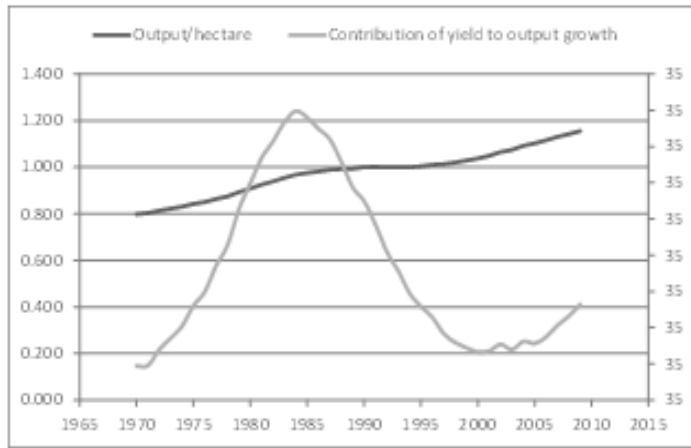

(b) Growth rates of output per hectare

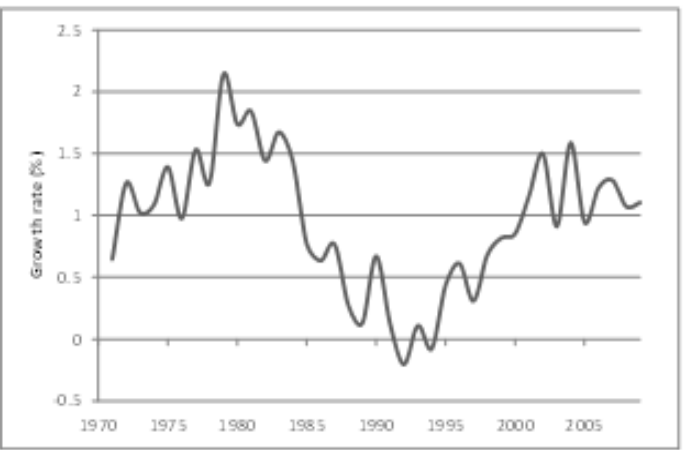

Source: Elaborated by authors using FAOSTAT (2012).

Note: Output is gross output; land is area harvested.

$\mathrm{SSA}=$ Africa south of the Sahara.

If output per hectare has shown low levels and slow growth even during the recent period of fastgrowing agriculture, labor productivity has been even less dynamic. The evolution of the output-labor relationship shows that labor productivity in 2010 is only 19 percent higher than its level in 1970 (Figure 
4.6). Rural population growth in SSA is a big part of the explanation for this slow labor productivity growth, which was even negative during part of the 1980s.

Figure 4.6-Evolution of labor productivity, output, and number of economically active population in agriculture in SSA, 1970-2009 (index 1970= 1)

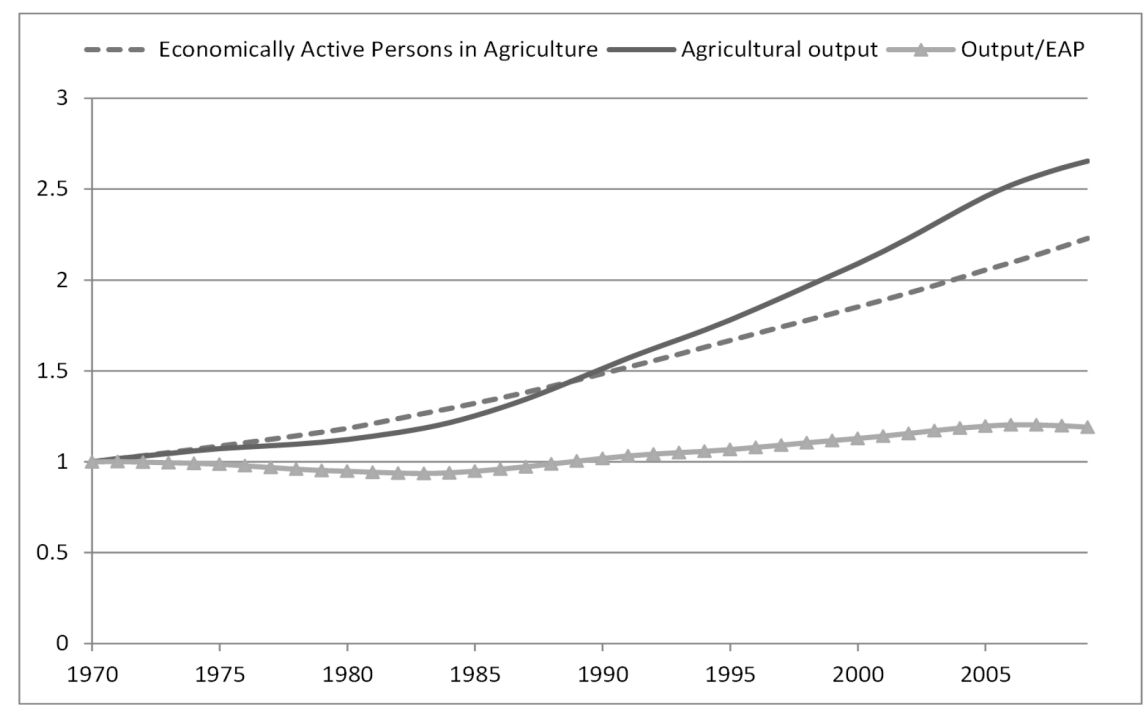

Source: Elaborated by authors using data from FAOSTAT (2012).

Note: EAP is economically active population in agriculture.

Figure 4.7 shows the joint evolution of labor and land productivity in 1970-2009, with the coordinates of each point in the line representing each year's value of labor and land productivity. The distance between points reflects how fast productivity is growing, and the total length of the line is an indicator of total productivity growth, whereas rays from the origin represent constant ratios of labor-land productivity.

Figure 4.7-Growth path of agriculture land-labor productivity space (1970-2009)

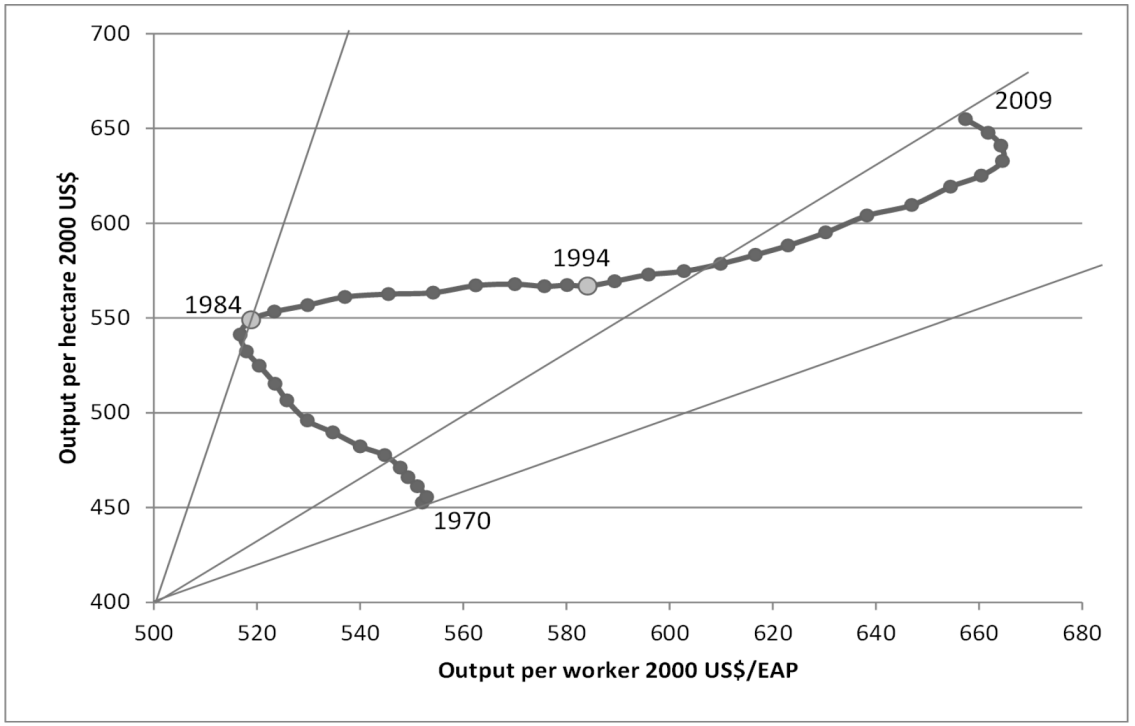

Source: Elaborated by authors using data from FAOSTAT (2012).

Note: EAP is economically active population in agriculture. 
We observe that before policy reforms in the 1980s and during the period of highest population growth, yields were driving growth (possibly due to higher labor intensity) while labor productivity decreased significantly. With policy changes in the 1980s and 1990s, labor productivity starts growing faster than yields, with the curve moving almost parallel to the x-axis until the early 1990s. During the period of accelerated growth of AgGDP (after 1994), labor and land productivity grow at about the same speed. By the end of the period there is a slowdown in growth (points are closer to each other) and a new change in direction with reduced labor productivity. This could just be the result of data errors but could also be a warning sign for future growth prospects.

We have shown so far that increased land use has been historically the major driver of agricultural growth in SSA. We also showed that aggregated output per hectare of harvested land has been increasing in the last 10 years although at modest rates (below 2 percent on average). We now focus on the 2000-2009 period to look at the contribution of different countries and crops to growth in output and output per hectare. To do this, we totally differentiate output growth into the contribution of each country as follows: $d Y=\sum_{j} a_{j} \cdot d y_{j}+\sum_{j} y_{j} \cdot d a_{j}$, where $d Y$ represents change in total crop output in SSA between periods $t-1$ and $t, a_{j}$ and $y_{j}$ are area and yield of country $j$ respectively, and $d a_{j}$ and $d y_{j}$ are changes in area and output per hectare in country $j$ between $t-1$ and $t$. Output growth decomposition by country is presented in Table 4.2 .

Similarly, we decompose total output growth within each country into the contribution of changes in yield and area of major crop groups: $d Y_{j}=\sum_{i} a_{i j} \cdot d y_{i j}+\sum_{i} y_{i j} \cdot d a_{i j}$, where $d Y_{j}$ represents change in total crop output in country $j$ between periods $t-1$ and $t, a_{i j}$ and $y_{i j}$ are respectively area and yield of crop $i$ in country $j$, and $d a_{i j}$ and $d y_{i j}$ are changes in area and yield of crop $i$ between $t-1$ and $t$. Results of the decomposition are presented in Figure 4.8.

We look first at Table 4.2 showing that yield and area contributed almost equally to crop output growth between 2001 and 2010. Not surprisingly, seven large agriculture producers (Ethiopia, Ghana, Nigeria, Tanzania, Sudan, Angola, and Cameroon) explain almost 60 percent of total output growth, with Nigeria, Ethiopia, and Ghana explaining most of the growth in output per hectare.

Table 4.2-Contribution of changes in crop output per hectare and total crop area in different countries to SSA's crop output growth, 2001-2010 (\%)

\begin{tabular}{lrrr}
\hline & Output/Hectare & Crop Area & Output Change \\
\hline Ethiopia & 6.5 & 5.5 & 12.0 \\
Ghana & 6.0 & 4.0 & 10.0 \\
Nigeria & 20.6 & -11.8 & 8.8 \\
Tanzania & 0.7 & 7.5 & 8.2 \\
Sudan & 2.7 & 3.9 & 6.6 \\
Angola & 1.5 & 4.7 & 6.2 \\
Cameroon & 2.0 & 4.1 & 6.1 \\
Malawi & 3.6 & 1.9 & 5.5 \\
Niger & 2.2 & 2.5 & 4.8 \\
Mali & 2.2 & 2.4 & 4.6 \\
Kenya & 1.8 & 1.9 & 3.7 \\
Madagascar & 2.1 & 1.1 & 3.2 \\
Zambia & 1.0 & 2.0 & 3.0 \\
Rwanda & 1.9 & 1.0 & 2.8 \\
Uganda & -1.0 & 3.7 & 2.7 \\
Burkina Faso & 0.3 & 2.3 & 2.6 \\
Mozambique & 0.5 & 1.9 & 2.4 \\
Benin & 1.5 & 0.8 & 2.3 \\
Others & -2.4 & 6.9 & 4.5 \\
\hline Total & $\mathbf{5 3 . 6}$ & $\mathbf{4 6 . 4}$ & $\mathbf{1 0 0 . 0}$ \\
\hline
\end{tabular}

Source: Authors' calculation using FAOSTAT data.

Note: $\quad \mathrm{SSA}=$ Africa south of the Sahara. 
The decomposition of total output growth into the contribution of different crops in Figure 4.8 shows that total increase in output per hectare results from relatively small increases of yields and areas of several groups of crops. No particular group of crops appears to be driving output growth in the region. Rwanda, Malawi, Ghana, Madagascar, Benin, Cameroon, Angola, and Sierra Leone are the countries with the highest contribution of land productivity to output growth. Five of these countries show a significant contribution of yields of roots and tubers in total output growth, while three countries show increased yields of fruits and vegetables meaningfully contributing to growth. Only two countries show a major contribution of cereal output per hectare to total output growth (Madagascar and Sierra Leone).

A detailed analysis of yield growth in different crops and countries goes beyond the scope of this study. For instance, yield growth in cereals in most West African countries appears to be driven by higher rice yields. This could be related to technological developments in this crop (for example, Nerica rice). The point here is not to neglect these positive outcomes but to look at their contribution to overall agricultural growth. What we find is that the impact of these changes on overall growth has been small.

We conclude that there is no evidence of technical change driving growth in SSA. Increases in land and labor productivity have been modest; yield growth in cereals is still low in almost all countries, and the use of fertilizer remains below its levels in the late 1980s. We explore now the evidence for improved efficiency in agricultural production.

Figure 4.8-Contribution of changes in output per hectare and total crop area of different crops to individual SSA countries' output growth, 2001-2010
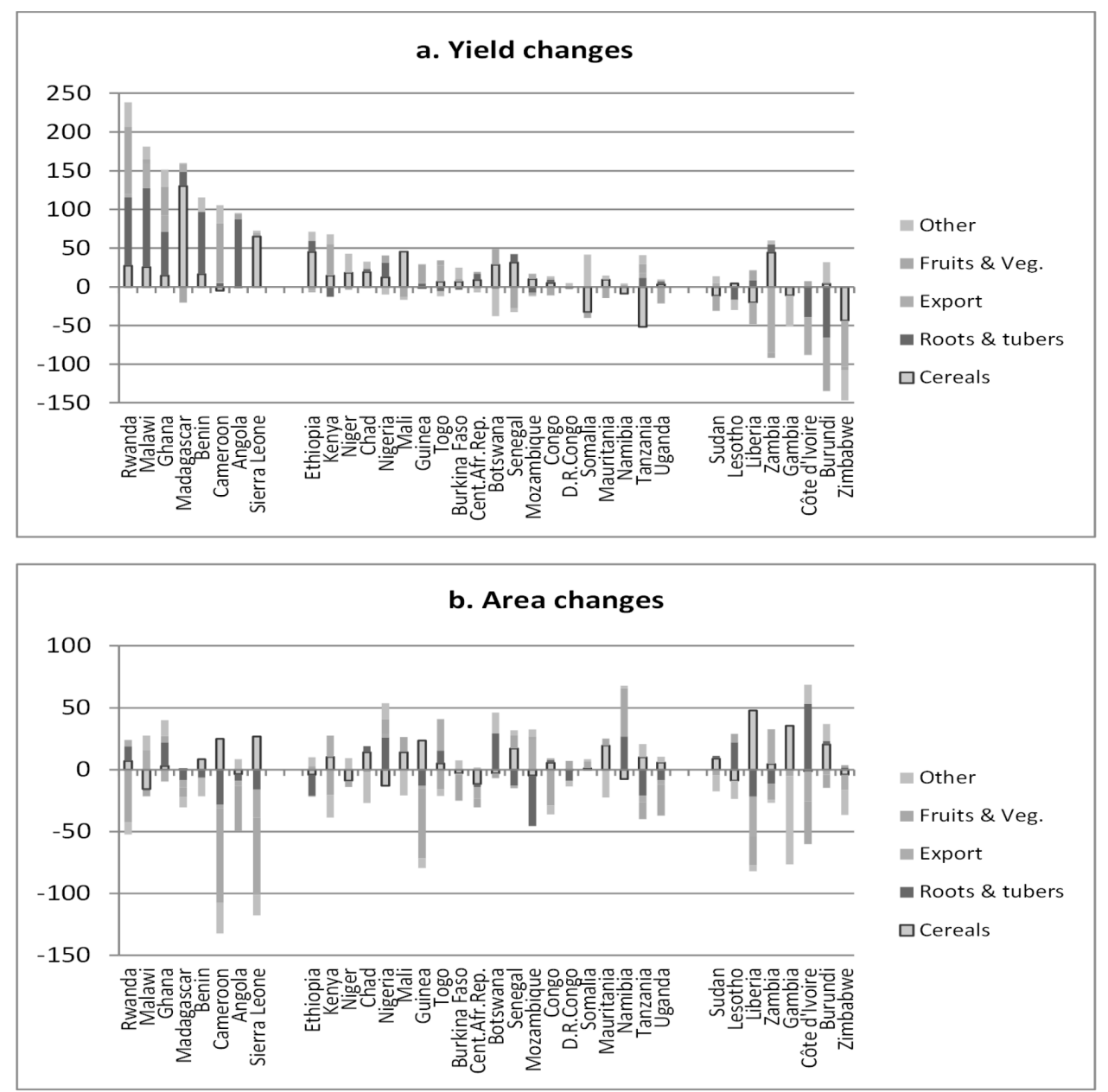

Source: Authors using FAOSTAT (2012).

Notes: (a) in value of gross output per hectare; (b) in 1,000s of hectares. SSA = Africa south of the Sahara. 


\section{Evidence on Efficiency and Catching Up}

To examine technical efficiency, we look at changes in resource allocation and in the structure and final destination of output. From that, we then test whether the gains in efficiency have been mostly about catching up to historical levels.

\section{Changes in Resource Allocation and in the Structure of Output}

We use here a measure of change in output composition between two periods used by Gutierrez de Pineres and Ferrantino (1997) among others. This measure is calculated as $\operatorname{CSX}=\sum_{i} \min \left(s_{i, t} s_{i, t-1}\right)$, where $s i, t$ is the share of commodity i in total output in period t. CSX takes values between 0 and 1 . A value of 0 means that none of the products produced in $t-1$ is produced in $t$. On the other hand, a value of 1 means that exactly the same product composition is found in period $t-1$ and $t$. Figure 4.9 shows the evolution of CSX for SSA.

\section{Figure 4.9-Evolution of an index of change in output composition (CSX) for agricultural production}

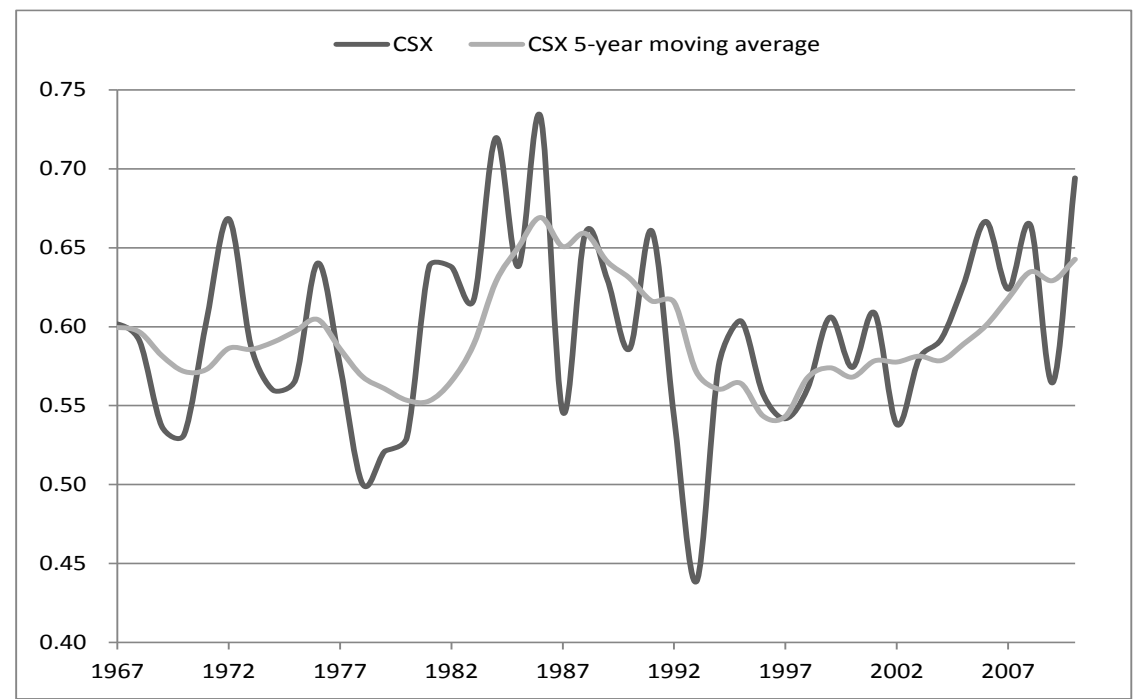

Source: Elaborated by authors using data from FAOSTAT (2012).

Note: The index is calculated as $C S X=\sum_{i} \min \left(s_{i, t} s_{i, t-1}\right)$, where $i$ are commodities produced and $s$ is the share of commodity $i$ in a particular year. Information from FAOSTAT on 58 agricultural products was used to calculate the index.

Whereas higher numbers of the index in Figure 4.9 mean stability in terms of the output composition, the moving average of the index gives a better idea of the trend. The index shows that the composition of agricultural production in SSA tends to become more stable during periods of sustained growth (1995-2010). On the other hand, periods of economic crisis and policy changes result in increasing instability in output composition, leading to changes in the structure of production (19851994). A possible interpretation of these results is that agriculture in SSA went through a period of adjustment in the late 1980s and early 1990s with changes in output composition that together with other changes in the economic environment faced by agricultural producers contributed to accelerate growth.

Changes in output structure during periods of crises do not necessarily mean permanent or substantial restructuring of production. Table 4.3 shows that some changes occurred in the structure of output in SSA; however, it is difficult to establish the incidence of these changes in production efficiency. Considering the output structure observed in 1975-1980 as that of agricultural production before structural adjustment programs and policy changes, the postcrisis output structure shows higher shares of 
staple crops (cereals and roots and tubers), which increased from 27 to 32 percent, and a reduction of the share of fruits. All other commodity groups show relatively stable shares in total output.

Table 4.3-Share of different groups of commodities in total output of selected SSA countries

\begin{tabular}{lrrrrr}
\hline & $\mathbf{1 9 6 5 - 7 0}$ & $\mathbf{1 9 7 5 - 8 0}$ & $\mathbf{1 9 8 5 - 9 0}$ & $\mathbf{1 9 9 5 - 0 0}$ & $\mathbf{2 0 0 5 - 1 0}$ \\
\hline Cereals, total & 13.0 & 12.7 & 14.5 & 13.6 & 13.6 \\
Roots and tubers, total & 14.5 & 14.5 & 15.5 & 18.2 & 18.2 \\
Fruit excl. melons, total & 16.3 & 19.3 & 17.7 & 16.0 & 14.6 \\
Cattle meat & 10.4 & 10.7 & 10.1 & 8.3 & 10.2 \\
Traditional export crops & 7.7 & 6.9 & 6.6 & 6.8 & 6.5 \\
Vegetables primary & 6.8 & 7.2 & 7.5 & 8.6 & 7.9 \\
Groundnuts, with shell & 8.0 & 6.1 & 4.5 & 5.5 & 5.1 \\
Pulses, total & 3.5 & 3.3 & 3.2 & 3.3 & 3.6 \\
Cow milk, whole, fresh & 3.9 & 4.1 & 5.1 & 4.7 & 5.7 \\
Sheep meat & 2.9 & 3.1 & 3.0 & 3.3 & 3.7 \\
Cotton & 2.3 & 1.8 & 1.7 & 1.5 & 1.1 \\
Sugar cane & 0.9 & 1.3 & 1.5 & 1.2 & 1.2 \\
Poultry & 1.9 & 2.6 & 2.9 & 2.5 & 2.5 \\
Other & 8.0 & 7.0 & 6.0 & 6.0 & 6.0 \\
\hline Total & $\mathbf{1 0 0}$ & $\mathbf{1 0 0}$ & $\mathbf{1 0 0}$ & $\mathbf{1 0 0}$ & $\mathbf{1 0 0}$ \\
\hline
\end{tabular}

Source: Elaborated by authors based on FAOSTAT (2012).

Note: $\quad \mathrm{SSA}=$ Africa south of the Sahara.

\section{Changes in the Final Destination of Output}

One way performance of agriculture could be affected is through changes in trade policy and the macroeconomic environment affecting trade and competitiveness of exports in international markets and of domestic production with respect to imports. Figure 4.10 shows the evolution of SSA's agriculture openness to trade and the export-to-import ratio of agricultural commodities. The figure shows a substantial change in the openness of agriculture in the early 1990s after years of decline. In two years the share of trade in AgGDP increased from 23 to 35 percent. The immediate effect of that trade shock was an increase in agricultural exports relative to imports. The trend reversed after 1996 when imports started growing faster than exports. At present, SSA is exporting a smaller share of total agricultural output than in 1980 but has increased imports significantly. Further analysis is needed, but the observed changes suggest a growing importance of domestic markets facing greater competition from imports. Some of the changes could have translated into increased production efficiency given the available technologies. 
Figure 4.10 — Trade openness of agriculture and evolution of the export/import ratio

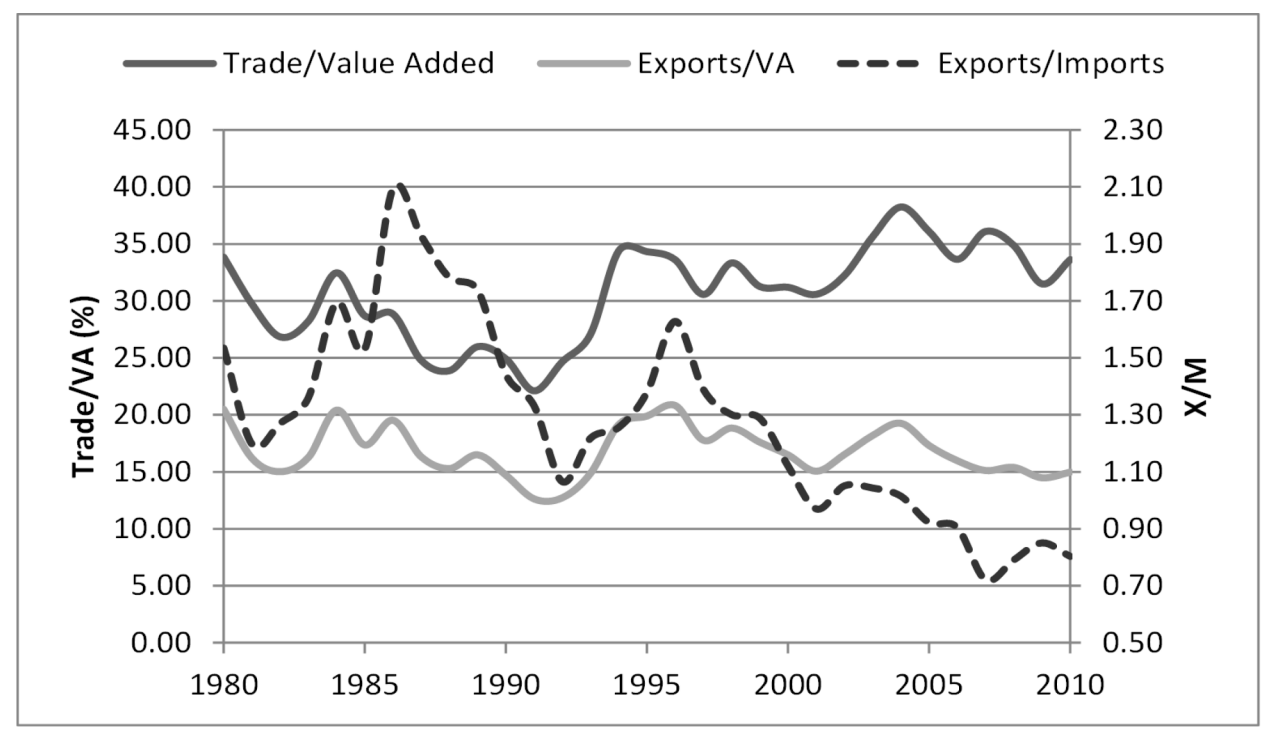

Source: Authors' calculation based on FAOSTAT (2012).

\section{Recovery and Catching Up to Historical Production Levels}

To test whether SSA's agricultural growth in recent years has been more about catching up to historical production levels after significant productivity losses during the pre-reform years, we check for evidence on efficiency gains. To look at this issue we use a larger sample of countries and measure agriculture value added per capita of rural population. The evolution of AgGDP per capita during 1970-2010 in Figure 4.11 reflects the period of bad performance and poor policies of the 1970s and 1980s that resulted in negative growth between 1975 and 1983. The period between 1985 and 2000 shows a series of fluctuations and changes in AgGDP per capita without a clear trend. It is only after 2000 that agriculture in the region takes off.

Figure 4.11-Evolution of AgGDP per capita of rural population (simple average of AgGDP of 32 countries)

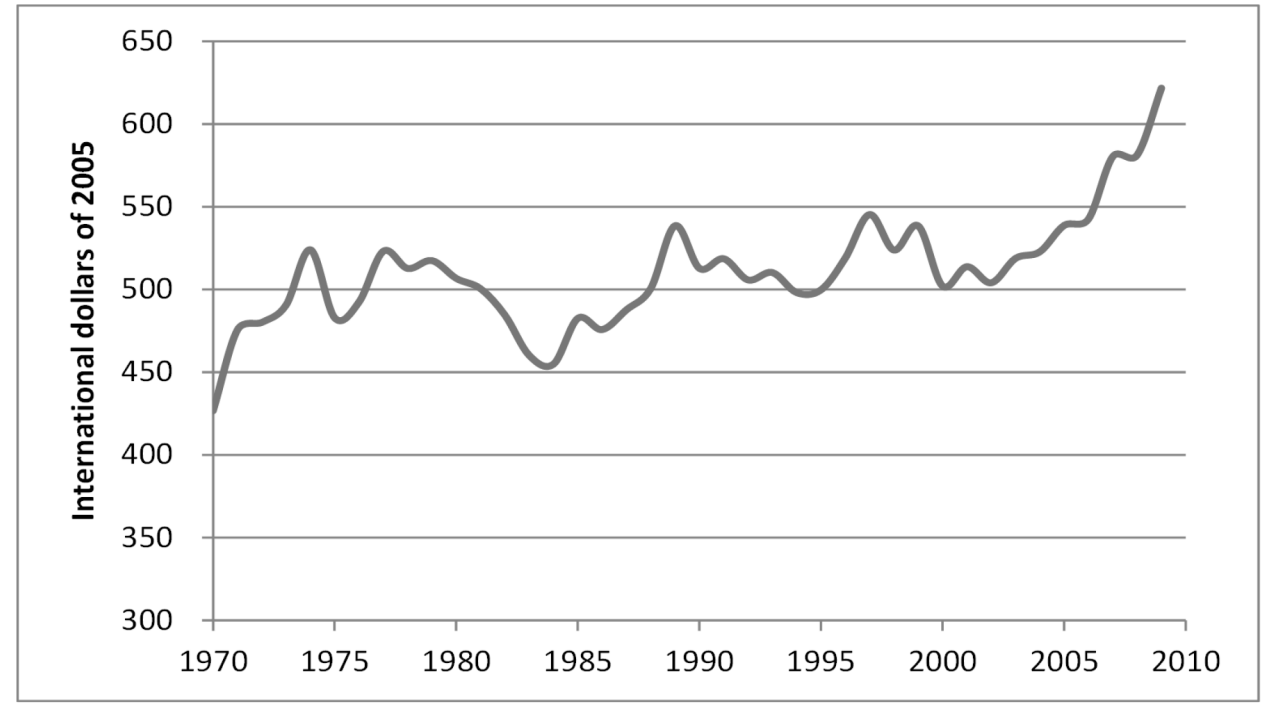

Source: Elaborated by authors based on data from Penn World Tables (Heston, Summers, and Aten 2012) and World Bank (2012). 
Performance by country in different periods is presented in Table 4.4. We observe that the bad performance of the 1970s and 1980s was a regional phenomenon. The simple average of growth rates for 31 countries is negative and only 35 percent of those countries show positive growth rates. The situation changes only in the 2000s where we observe that 65 percent of the countries show positive growth rates. The 1985-2000 period appears to be a transition for the region, with half of the countries showing positive growth rates.

Table 4.4-Growth of AgGDP per capita in different periods (\%) sorted by growth in 2000-2009

\begin{tabular}{|c|c|c|c|c|}
\hline & 1975-1983 & 1985-1994 & 1995-2000 & 2000-2009 \\
\hline Zambia & -3.35 & 0.93 & -6.54 & 10.38 \\
\hline Nigeria & -9.42 & 0.88 & -1.17 & 7.37 \\
\hline Ethiopia & 0.88 & -1.08 & 2.73 & 6.14 \\
\hline Botswana & -9.27 & -3.72 & 1.35 & 4.49 \\
\hline Sierra Leone & 1.39 & -1.40 & 0.66 & 3.89 \\
\hline Guinea-Bissau & -1.11 & 3.42 & 6.78 & 3.80 \\
\hline Côte d'lvoire & -0.50 & 1.46 & -1.16 & 3.11 \\
\hline Rwanda & -1.19 & -3.11 & 1.45 & 3.01 \\
\hline South Africa & -6.36 & 3.86 & -0.72 & 2.90 \\
\hline Ghana & -5.41 & 0.91 & -2.94 & 2.86 \\
\hline Togo & 0.74 & 0.92 & 11.92 & 2.79 \\
\hline Tanzania & -0.02 & -2.35 & -2.10 & 2.39 \\
\hline Burkina Faso & -0.14 & -5.05 & -0.13 & 2.31 \\
\hline Gabon & 2.03 & -0.70 & -3.41 & 0.89 \\
\hline Central African Republic & -0.80 & 0.67 & -7.14 & 0.72 \\
\hline Mali & 0.66 & -1.17 & -4.73 & 0.53 \\
\hline Madagascar & -2.26 & 6.08 & -2.57 & 0.43 \\
\hline Cameroon & 5.45 & -3.61 & 4.31 & 0.24 \\
\hline Senegal & -3.56 & -0.71 & -9.24 & 0.18 \\
\hline Mozambique & -1.66 & 3.08 & -0.10 & 0.01 \\
\hline Malawi & -0.99 & -2.41 & 2.21 & -0.09 \\
\hline Sudan & -1.59 & -0.15 & 0.29 & -0.13 \\
\hline Congo, Republic & 1.67 & -0.02 & 1.02 & -0.50 \\
\hline Kenya & -1.13 & 2.84 & 0.08 & -0.70 \\
\hline Niger & -3.92 & -1.01 & -1.26 & -0.72 \\
\hline Uganda & -3.72 & -0.61 & -0.12 & -0.98 \\
\hline DR Congo & 4.37 & 2.82 & 0.38 & -1.88 \\
\hline Benin & 2.00 & -8.12 & 10.13 & -2.44 \\
\hline Burundi & 0.26 & 0.21 & 5.21 & -2.97 \\
\hline Mauritania & 0.29 & 3.22 & -0.39 & -3.31 \\
\hline Chad & -1.51 & 6.04 & 1.77 & -4.77 \\
\hline Average & -1.23 & 0.07 & 0.21 & 1.29 \\
\hline$\%$ of rates greater than zero & 35.48 & 51.61 & 51.61 & 35.48 \\
\hline
\end{tabular}

Source: Authors' estimation based on FAOSTAT (2012).

Note: $\operatorname{AgGDP}=$ agricultural gross domestic product

We look now at the relation between growth in the 2000s and the poor performance of 1975 1985. To do that, we use the average growth rates presented in Table 4.3 and we regress rates for the different periods after 1985 against average rates from 1975-1983. Results are presented in Table 4.5 and Figure 4.12. The only significant coefficient is the one for the regression using growth rates of 2000-2010 as dependent variable. The negative and significant coefficient means that countries showing the worst growth performance in 1975-1983 are the ones expected to grow faster in 2000-2010. No significant correlation was found between growth in 1975-1983 and growth in the periods that followed. The coefficients obtained for the two intermediate periods are positive but not significant. Clearly, efficiency gains have been quite high during the early postreform period, especially among countries that had experienced dramatic declines in productivity in the past, indicating that for most countries, much of the growth in TFP during this period could be a story of a recovery to historical productivity levels. 
Table 4.5-Coefficients from regressions of AgGDP growth rates for different periods

\begin{tabular}{lrr}
\hline & Independent Variable: Growth Rates for 1975-1983 \\
\hline Dependent variable growth rates for the period: & Coefficient & t-statistics \\
\hline $1985-1994$ & -0.155 & -0.908 \\
$1995-2000$ & 0.713 & 1.722 \\
$1985-2000$ & 0.052 & 0.408 \\
$2000-2009$ & -0.382 & $-2.326^{\mathrm{a}}$ \\
\hline
\end{tabular}

Source: Authors' estimation.

Notes: ${ }^{a}$ Statistically significant at the $5 \%$ level.

AgGDP $=$ agricultural gross domestic product.

Figure 4.12 - Relationship between AgGDP per capita growth in 1975-1983 and growth in 20002010

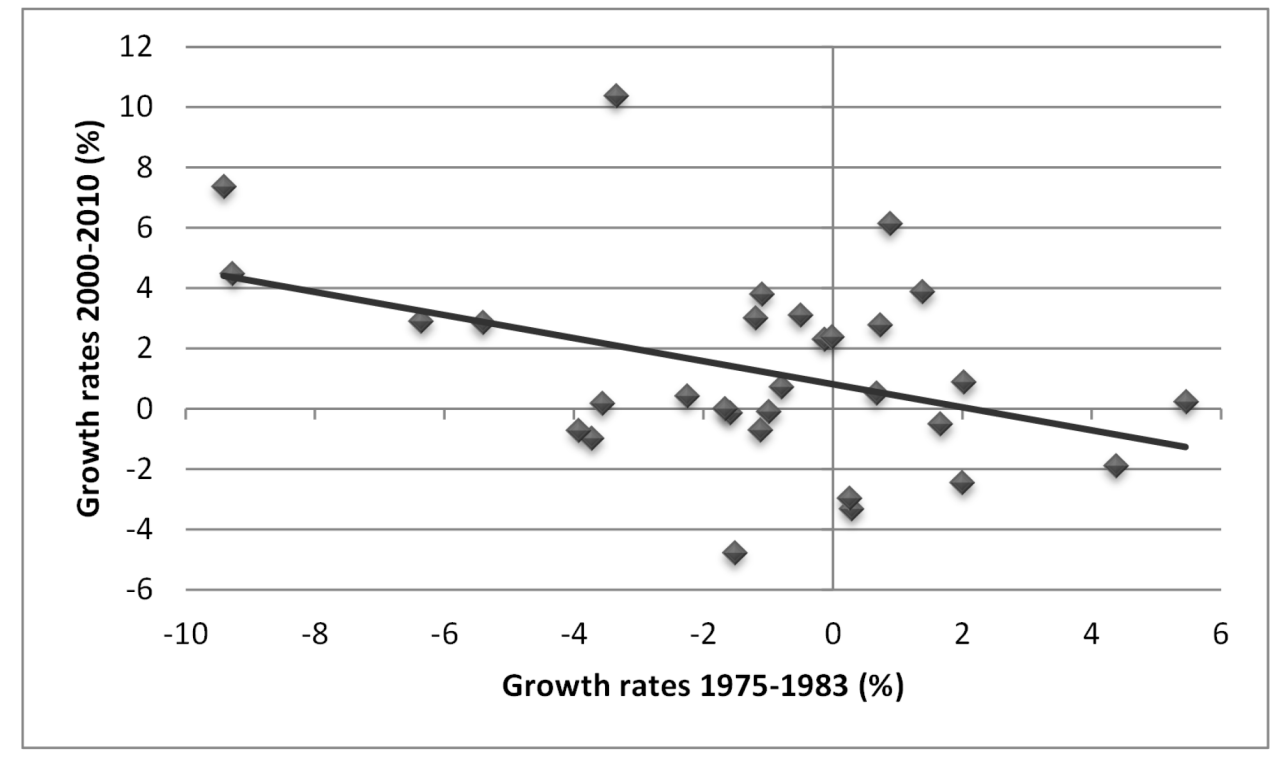

Source: Authors' estimation.

Note: $\quad \operatorname{AgGDP}=$ agricultural gross domestic product. 


\section{SUMMARY CONCLUSION AND POLICY IMPLICATIONS}

Results from our analysis show both bad and good news for the current and future prospects of African agricultural growth. The bad news is that two-thirds of the positive agricultural growth in recent years is explained by growth in domestic prices, which could be hiding very different situations in terms of performance based on productivity growth. Although claims of a booming African agriculture may be too strong a conclusion, therefore, the clear evidence of a recovery with sustained productivity growth in the most recent decade is no small achievement. This is irrespective of any potential measurement errors and problems with data quality, as our primary focus has been to shed light on the evolution and underlying patterns of agriculture's performance, and not to determine its absolute values.

We conclude as in Nin Pratt and $\mathrm{Yu}$ (2008) that a changing policy environment and increased attention to agriculture in the postreform period has had a major effect on overall productivity growth based on technical efficiency gains. It took 15 years of transition with mixed results and a favorable international environment to see recovery and sustained agricultural growth in the region. Even after that long transition, we find that growth in recent years is still explained, at least in part, as a recovery from the crisis of the lost decade of 1975-1985. Technical change, on the other hand, played only an insignificant role in explaining recent growth. Increases in land and labor productivity have been modest; yield growth in cereals is still low in almost all countries; and the use of fertilizer remains below its levels in the late 1980s. So although the recovery is good news, much more remains to be done to sustain future growth.

More important, however, we also conclude from our analysis that favorable domestic prices have indeed played an even bigger role than the positive changes we observed in overall productivity. Domestic markets have grown in importance and will play a critical role in affecting any prospects for overall sector growth in the future. Domestic demand for agricultural commodities is outpacing agricultural production and leading to a growing reliance on imports. At the same time, agricultural exports have not grown as fast as imports either. Presently, SSA is exporting a smaller share of total agricultural output than it did in 1980. A key challenge for African countries, therefore, is how well they can govern the current windfall gains from high commodity prices in global and domestic markets together with the one-time effect of policy changes.

Under these circumstances, countries need to promote productivity growth through technical change among those commodities for which domestic demand is rapidly increasing, such as food staples among both urban and rural consumers. Previous studies have shown that focusing on food staples will likely produce a win-win strategy by enabling the transformation of the agricultural sector and contributing to overall economic growth and food security among millions of smallholder producers and consumers. Similar efforts are needed to increase productivity of export commodities, which have been stagnant for decades, resulting in decreasing world market shares and growing agricultural trade deficits. This is even more important at a time when African governments and donors have already increased their commitments to revitalizing the sector and are now in the process of prioritizing specific investments and policy and institutional reforms in order to stimulate growth and economic transformation of the sector. 


\section{APPENDIX: SUPPLEMENTARY TABLES}

Table A.1-Share of selected countries in agricultural production and resource use (percentage of total in SSA not including South Africa)

\begin{tabular}{|c|c|c|c|c|c|c|}
\hline & Output & $\begin{array}{c}\text { Agricultural } \\
\text { Area }\end{array}$ & $\begin{array}{c}\text { Harvested } \\
\text { Area }\end{array}$ & Labor & Livestock & Fertilizer \\
\hline \multicolumn{7}{|c|}{ Countries included in this study } \\
\hline Botswana & 0.20 & 2.76 & 0.07 & 0.16 & 0.81 & 0.32 \\
\hline Cameroon & 2.99 & 0.71 & 2.49 & 1.90 & 2.11 & 2.69 \\
\hline Chad & 1.17 & 5.22 & 1.99 & 1.52 & 2.89 & 1.21 \\
\hline Côte d'Ivoire & 4.77 & 2.16 & 3.75 & 1.51 & 0.63 & 5.01 \\
\hline D.R. Congo & 2.94 & 2.24 & 3.16 & 7.18 & 0.50 & 0.24 \\
\hline Ethiopia & 6.57 & 4.41 & 7.65 & 16.42 & 18.02 & 14.64 \\
\hline Ghana & 4.62 & 1.58 & 3.47 & 3.00 & 0.80 & 3.23 \\
\hline Guinea & 1.52 & 1.49 & 1.71 & 1.94 & 1.32 & 0.19 \\
\hline Kenya & 4.80 & 2.80 & 2.58 & 6.67 & 5.17 & 10.72 \\
\hline Lesotho & 0.10 & 0.24 & 0.12 & 0.19 & 0.33 & 0.56 \\
\hline Madagascar & 2.55 & 4.32 & 1.62 & 3.54 & 2.96 & 0.74 \\
\hline Malawi & 1.91 & 0.58 & 1.91 & 2.41 & 0.46 & 7.29 \\
\hline Mali & 2.17 & 4.22 & 2.55 & 1.51 & 3.72 & 3.41 \\
\hline Mozambique & 1.60 & 5.23 & 2.55 & 4.36 & 0.68 & 0.98 \\
\hline Namibia & 0.36 & 4.11 & 0.18 & 0.14 & 0.94 & 0.10 \\
\hline Nigeria & 27.57 & 8.79 & 23.83 & 6.55 & 8.65 & 22.21 \\
\hline Rwanda & 1.32 & 0.23 & 0.94 & 2.13 & 0.47 & 0.39 \\
\hline Senegal & 1.03 & 0.87 & 1.36 & 1.87 & 1.61 & 1.62 \\
\hline Sudan & 6.52 & 13.92 & 7.22 & 3.62 & 16.99 & 4.46 \\
\hline Tanzania & 5.23 & 3.78 & 6.06 & 8.36 & 6.09 & 2.93 \\
\hline Uganda & 4.42 & 1.33 & 3.92 & 5.41 & 2.64 & 0.74 \\
\hline Zambia & 0.95 & 2.31 & 0.81 & 1.60 & 0.98 & 2.86 \\
\hline Subtotal & 85.30 & 73.29 & 79.97 & 81.98 & 78.75 & 86.53 \\
\hline \multicolumn{7}{|l|}{ Other countries } \\
\hline Angola & 1.80 & 6.16 & 1.84 & 2.88 & 1.41 & 0.87 \\
\hline Benin & 1.55 & 0.31 & 1.28 & 0.82 & 0.66 & 0.14 \\
\hline Burkina Faso & 1.77 & 1.22 & 2.90 & 3.34 & 3.64 & 4.11 \\
\hline Burundi & 0.80 & 0.22 & 0.63 & 1.84 & 0.22 & 0.15 \\
\hline Cape Verde & 0.04 & 0.01 & 0.03 & 0.02 & 0.04 & 0.02 \\
\hline C. African Rep. & 0.70 & 0.45 & 0.52 & 0.65 & 1.24 & 0.04 \\
\hline Comoros & 0.05 & 0.01 & 0.06 & 0.11 & 0.02 & 0.02 \\
\hline Congo & 0.28 & 1.10 & 0.16 & 0.27 & 0.06 & 0.10 \\
\hline Djibouti & 0.05 & 0.18 & 0.01 & 0.14 & 0.14 & 0.02 \\
\hline Equatorial Guinea & 0.04 & 0.02 & 0.05 & 0.09 & 0.00 & 0.01 \\
\hline Gabon & 0.21 & 0.53 & 0.12 & 0.10 & 0.04 & 0.19 \\
\hline Gambia & 0.10 & 0.07 & 0.21 & 0.30 & 0.15 & 0.18 \\
\hline Guinea-Bissau & 0.20 & 0.16 & 0.24 & 0.23 & 0.22 & 0.17 \\
\hline Liberia & 0.33 & 0.27 & 0.28 & 0.44 & 0.06 & 0.02 \\
\hline Mauritania & 0.37 & 4.25 & 0.20 & 0.37 & 1.58 & 0.20 \\
\hline Mauritius & 0.20 & 0.01 & 0.04 & 0.03 & 0.05 & 2.32 \\
\hline Niger & 2.22 & 4.63 & 7.79 & 2.05 & 4.15 & 0.36 \\
\hline Reunion & 0.14 & 0.01 & 0.03 & 0.00 & 0.07 & 0.34 \\
\hline Sao Tome and Prince & 0.02 & 0.00 & 0.02 & 0.02 & 0.00 & 0.00 \\
\hline Sierra Leone & 0.50 & 0.36 & 0.61 & 0.68 & 0.29 & 0.02 \\
\hline Somalia & 1.28 & 4.70 & 0.45 & 1.24 & 5.01 & 0.03 \\
\hline Swaziland & 0.23 & 0.13 & 0.08 & 0.07 & 0.20 & 0.48 \\
\hline Swaziland & 0.00 & 0.00 & 0.00 & 0.02 & 0.00 & 0.00 \\
\hline Togo & 0.59 & 0.27 & 0.81 & 0.66 & 0.30 & 0.90 \\
\hline Zimbabwe & 1.22 & 1.63 & 1.68 & 1.67 & 1.70 & 2.78 \\
\hline Subtotal & 14.70 & 26.71 & 20.03 & 18.02 & 21.25 & 13.47 \\
\hline
\end{tabular}

Source: Authors' calculation based on FAOSTAT data.

Note: Output is agricultural gross production in constant 2004-2006 US\$1,000. Agricultural area includes cropland and permanent pasture. Area harvested is area under temporary and permanent crops. Agricultural labor is economically active persons in agriculture $(1,000 \mathrm{~s}$, male + female). Livestock is head of animal units (number of cattle-equivalents), and fertilizer is total consumption of fertilizer in tons. $\mathrm{SSA}=$ Africa south of the Sahara. 
Table A.2-Estimation results of translog agricultural GDP equation

\begin{tabular}{|c|c|c|}
\hline & Translog & Translog and Input Demands \\
\hline$\alpha_{M}$ & $\begin{array}{c}-0.174 \\
(0.163)\end{array}$ & $\begin{array}{c}-0.030 \\
(0.032)\end{array}$ \\
\hline$\alpha_{X}$ & $\begin{array}{l}1.767^{* * *} \\
(0.354)\end{array}$ & $\begin{array}{c}0.153^{\star * *} \\
(0.026)\end{array}$ \\
\hline$\alpha_{C}$ & $\begin{array}{l}-0.592 \\
(0.370)\end{array}$ & $\begin{array}{c}0.876^{\star * *} \\
(0.033)\end{array}$ \\
\hline$\beta_{L}$ & $\begin{array}{c}0.947^{* * *} \\
(0.055)\end{array}$ & $\begin{array}{c}0.404^{\star * *} \\
(0.014)\end{array}$ \\
\hline$\beta_{K}$ & $\begin{array}{c}-0.394^{* * *} \\
(0.049)\end{array}$ & $\begin{array}{c}0.112^{\star * *} \\
(0.014)\end{array}$ \\
\hline$\beta_{L D}$ & $0.553^{* * *}$ & $0.515^{\star * *}$ \\
\hline$\gamma_{M M}$ & $\begin{array}{c}(0.026) \\
-0.643^{* * *} \\
(0.208)\end{array}$ & $\begin{array}{c}(0.002) \\
-0.100^{* * *} \\
(0.033)\end{array}$ \\
\hline$\gamma_{M X}$ & $\begin{array}{l}0.270^{* *} \\
(0.116)\end{array}$ & $\begin{array}{c}0.070^{* * *} \\
(0.019)\end{array}$ \\
\hline$\gamma_{M C}$ & $\begin{array}{c}0.373^{* * *} \\
(0.133)\end{array}$ & $\begin{array}{c}0.030 \\
(0.026)\end{array}$ \\
\hline$\gamma_{X X}$ & $\begin{array}{c}-0.186^{\star *} \\
(0.083)\end{array}$ & $\begin{array}{c}0.061^{* * *} \\
(0.016)\end{array}$ \\
\hline$\gamma_{X C}$ & $\begin{array}{c}-0.084 \\
(0.071)\end{array}$ & $\begin{array}{c}-0.132^{* * *} \\
(0.016)\end{array}$ \\
\hline$\gamma_{C C}$ & $-0.288^{* * *}$ & $0.102^{\star * *}$ \\
\hline$\phi_{L L}$ & $\begin{array}{c}(0.107) \\
0.298^{* * *} \\
(0.026)\end{array}$ & $\begin{array}{c}(0.028) \\
0.019^{\star * *} \\
(0.006)\end{array}$ \\
\hline$\phi_{L K}$ & $\begin{array}{c}-0.253^{* * *} \\
(0.025)\end{array}$ & $\begin{array}{c}-0.053^{* * *} \\
(0.006)\end{array}$ \\
\hline$\phi_{L, L D}$ & $\begin{array}{c}-0.045^{\star * *} \\
(0.015)\end{array}$ & $\begin{array}{c}0.034^{\star * *} \\
(0.004)\end{array}$ \\
\hline$\phi_{K K}$ & $\begin{array}{c}-0.173^{* * *} \\
(0.043)\end{array}$ & $\begin{array}{l}-0.017^{*} \\
(0.010)\end{array}$ \\
\hline$\phi_{K, L D}$ & $\begin{array}{c}0.426^{* * *} \\
(0.032)\end{array}$ & $\begin{array}{l}0.071^{* * *} \\
(0.006)\end{array}$ \\
\hline$\phi_{L D, L D}$ & $\begin{array}{c}-0.381^{* * *} \\
(0.027)\end{array}$ & $\begin{array}{c}-0.105^{\star * *} \\
(0.005)\end{array}$ \\
\hline$\delta_{M L}$ & $\begin{array}{c}-0.199^{* * *} \\
(0.065)\end{array}$ & $\begin{array}{c}0.154^{* * *} \\
(0.009)\end{array}$ \\
\hline$\delta_{X L}$ & $\begin{array}{c}-0.066^{* *} \\
(0.033)\end{array}$ & $\begin{array}{c}-0.078^{* * *} \\
(0.007)\end{array}$ \\
\hline$\delta_{C L}$ & $0.264^{* * *}$ & $-0.076^{* * *}$ \\
\hline$\delta_{M K}$ & $\begin{array}{c}(0.046) \\
0.209^{* * *} \\
(0.076)\end{array}$ & $\begin{array}{c}(0.009) \\
-0.072^{* \star *} \\
(0.012)\end{array}$ \\
\hline$\delta_{X K}$ & $\begin{array}{c}-0.018 \\
(0.046)\end{array}$ & $\begin{array}{c}0.039^{* * *} \\
(0.008)\end{array}$ \\
\hline$\delta_{C K}$ & $\begin{array}{c}-0.191^{\star * *} \\
(0.055)\end{array}$ & $\begin{array}{c}0.034^{\star * *} \\
(0.010)\end{array}$ \\
\hline$\delta_{M, L D}$ & $\begin{array}{l}-0.010 \\
(0.062)\end{array}$ & $\begin{array}{c}-0.082^{* * *} \\
(0.010)\end{array}$ \\
\hline$\delta_{X, L D}$ & $\begin{array}{c}-0.098^{* * *} \\
(0.035)\end{array}$ & $\begin{array}{c}0.036^{* * *} \\
(0.005)\end{array}$ \\
\hline
\end{tabular}


Table A.2-Continued

\begin{tabular}{|c|c|c|}
\hline & Translog & $\begin{array}{l}\text { Translog and Input } \\
\text { Demands }\end{array}$ \\
\hline$\delta_{C, L D}$ & $\begin{array}{l}0.084^{* *} \\
(0.037)\end{array}$ & $\begin{array}{l}0.039^{* * *} \\
(0.005)\end{array}$ \\
\hline$\delta_{M t}$ & $\begin{array}{c}0.002 \\
(0.007)\end{array}$ & $\begin{array}{c}-0.005^{* * *} \\
(0.001)\end{array}$ \\
\hline$\delta_{X t}$ & $\begin{array}{l}-0.001 \\
(0.005)\end{array}$ & $\begin{array}{l}0.001 \\
(0.001)\end{array}$ \\
\hline$\delta_{C t}$ & $\begin{array}{l}-0.002 \\
(0.004)\end{array}$ & $\begin{array}{l}0.003^{*} \\
(0.002)\end{array}$ \\
\hline$\phi_{L t}$ & $\begin{array}{c}-0.007^{* * *} \\
(0.002)\end{array}$ & $\begin{array}{l}-0.001 \\
(0.001)\end{array}$ \\
\hline$\phi_{K t}$ & $\begin{array}{l}0.005^{* *} \\
(0.002)\end{array}$ & $\begin{array}{l}0.006^{* * *} \\
(0.001)\end{array}$ \\
\hline$\phi_{L D, t}$ & $\begin{array}{c}0.002 \\
(0.002)\end{array}$ & $\begin{array}{c}-0.005^{* * *} \\
(0.000)\end{array}$ \\
\hline $\mathrm{t}$ & $\begin{array}{l}-0.020^{* *} \\
(0.010)\end{array}$ & $\begin{array}{l}0.016^{* *} \\
(0.008)\end{array}$ \\
\hline $\mathrm{tt}$ & $\begin{array}{l}0.001^{* * *} \\
(0.001)\end{array}$ & $\begin{array}{l}0.000 \\
(0.000)\end{array}$ \\
\hline Constant & $\begin{array}{c}-5.966^{* * *} \\
(0.261)\end{array}$ & $\begin{array}{c}-6.902^{* * *} \\
(0.065)\end{array}$ \\
\hline Observations & 775 & 744 \\
\hline R-squared & 0.860 & 0.721 \\
\hline
\end{tabular}

Source: Authors' estimation.

Note: $\quad$ GDP $=$ gross domestic product. 


\section{REFERENCES}

Alene, Arega D. 2010. "Productivity Growth and the Effects of R\&D in African Agriculture." Agricultural Economics 41 (3-4): 223-238.

Alene, Arega D., and Ousmane Coulibaly. 2009. "The Impact of Agricultural Research on Productivity and Poverty in Sub-Saharan Africa." Food Policy 34 (2): 198-209.

Alston, Julian, Michele Marra, Philip Pardey, and T. J. Wyatt. 2000. "Research Returns Redux: A Meta-analysis of the Returns to Agricultural R\&D." Australian Journal of Agricultural and Resource Economics 44: 185215.

ASTI (Agricultural Science and Technology Indicators). 2011. ASTI database. www.asti.cgiar.org/data.

Badiane, Ousman, Sunday Odjo, and John Ulimwengu. 2011. Emerging Policies and Partnerships under CAADP. Implications for Long-Term Growth, Food Security, and Poverty Reduction. IFPRI Discussion Paper 01145. Washington, DC: International Food Policy Research Institute.

Beintema, Nienke, and Gert-Jan Stads. 2011. African Agricultural R\&D in the New Millennium: Progress for Some, Challenges for Many. IFPRI Food Policy Report 24. Washington, DC: International Food Policy Research Institute.

Benin, Sam, Michael Johnson, Kipo Jimah, Joe Taabazuing, Albert Tenga, Emmanuel Abokyi, Gamel Nasser, Gerald Ahorbo, and Victor Owusu. 2011. Evaluation of Four Special Initiatives of the Ministry of Food and Agriculture, Government of Ghana. Project report. Washington, DC: International Food Policy Research Institute.

Block, Steven. 1995. “The Recovery of Agricultural Productivity in Sub-Saharan Africa.” Food Policy 20 (5): 385405.

. 2010. The Decline and Rise of Agricultural Productivity in Sub-Saharan Africa Since 1961. NBER Working Paper 16481. National Bureau of Economic Research.

Deaton, Angus. 1999. "Commodity Prices and Growth in Africa." Journal of Economic Perspectives 13 (3): $23-40$.

Diewert, W. Erwin and Catherine J. Morrison. 1986. “Adjusting Output and Productivity Indexes for Changes in the Terms of Trade." Economic Journal 96: 659-679.

FAOSTAT. 2012. Food and Agriculture Organization of the United Nations. Accessed May 24. http://faostat.fao.org/.

Fox, Kevin J., and Ulrich Kohli. 1997. "GDP Growth, Terms-of-Trade Effects, and Total Factor Productivity." Revised version of a paper presented at the Conference on Environment, Trade, and Growth, Melbourn, Victoria, Australia, August 20-22, 1996.

Fuglie, Keith O., and Nicholas Rada. 2011. "Policies and Productivity Growth in African Agriculture." Conference Working Paper 19. Prepared for the ASTI/IFPRI-FARA Conference, Accra, Ghana, December 5-7.

Griliches, Zvi. 1992. The Search for R\&D Spillovers. NBER Working Paper 3768. National Bureau of Economic Research.

Gutierrez de Pineres, Sheila A., and Michael Ferrantino. 1997. "Export Diversification and Structural Dynamics in the Growth Process: The Case of Chile." Journal of Development Economics 52 (2): 375-391.

Heston, Alan, Robert Summers, and Bettina Aten. 2012. Penn World Table Version 7.1. Center for International Comparisons of Production, Income, and Prices, University of Pennsylvania. July.

Kherallah, Mylène, Christopher L. Delgado, Eleni Gabre-madhin, Nicholas Minot, and Michael Johnson. 2002. Reforming Agricultural Market Reforms in Sub-Saharan Africa. Baltimore: Johns Hopkins University Press.

Kohli, Ulrich. 1978. "A Gross National Product Function and the Derived Demand for Imports and Supply of Exports." Canadian Journal of Economics 11: 167-182. 
Kohli, Ulrich. 1991. Technology, Duality, and Foreign Trade: The GNP Function Approach to Modeling Imports and Exports. Ann Arbor, MI, US: University of Michigan Press.

Kohli, Ulrich. 2002. "Growth Accounting in the Open Economy." Revised version of a paper presented at the 1996 annual meeting of the Western Economic Society in San Francisco; the 1997 annual meeting of the Canadian Economic Association in St. John's, Newfoundland and Labrador; and the 1996 Georgia Productivity Workshop.

Kohli, Ulrich. 2004. "Real GDP, Real Domestic Income, and Terms-of-Trade Changes.” Journal of International Economics 62: 83-106.

Lipton, Michael. 2012. Learning from Others: Increasing Agricultural Productivity for Human Development in SubSaharan Africa. Working Paper 2012-007. United Nations Development Programme, Regional Bureau for Africa.

Lusigi, Angela, and Colin Thirtle. 1997. "Total Factor Productivity and the Effects of R\&D in African Agriculture." Journal of International Development 9 (4): 529-538.

Mullen, John. 2007. "The Returns from Research in Australian Broadacre Agriculture.” Australian Journal of Agricultural and Resource Economics 51: 359-384.

Mullen, John D., and T. L. Cox. 1995. "The Returns from Research in Australian Broadacre Agriculture." Australian Journal of Agricultural Economics 39: 105-128. . 1996. "Measuring Productivity Growth in Australian Broadacre Agriculture." Australian Journal of Agricultural Economics 40, 189-210.

Nin Pratt, Alejandro. 2011. "Agricultural R\&D Investment, Poverty, and Economic Growth in Sub-Saharan Africa: Prospects and Needs to 2050." Conference Working Paper 9. Prepared for the ASTI/IFPRI-FARA Conference, Accra, Ghana, December 5-7.

Nin Pratt, Alejandro, and Shenggen Fan. 2009. R\&D Investment in National and International Agricultural Research: An Ex-ante Analysis of Productivity and Poverty Impact. IFPRI Discussion Paper 986. Washington, DC: International Food Policy Research Institute.

Nin Pratt, Alejandro, and Bingxin Yu. 2008. An Updated Look at the Recovery of Agricultural Productivity in SubSaharan Africa. IFPRI Discussion Paper 787. Washington, DC: International Food Policy Research Institute.

OECD.StatExtracts. 2012. Creditor Reporting System. Available from: http://stats.oecd.org/index.aspx?DataSetCode=CRS1 [Accessed 8 May 2012].

Solow, Robert M. 1957. "Technical Change and the Aggregate Production Function." Review of Economics and Statistics, XXXIX (1957), 312-320.

Thirtle, Colin, David Hadley, and Robert Townsend. 1995. "Policy-Induced Innovation in Sub-Saharan African Agriculture: A Multilateral Malmquist Productivity Index Approach.” Development Policy Review 13 (4): $323-348$.

Weiser, R. 2005. "Research and Development, Productivity Spillovers: Empirical Evidences at the Firm Level." Journal of Economic Surveys 19: 587-621.

Woodland, Alan D. 1982. International Trade and Resource Allocation. Amsterdam: North Holland.

World Bank. 2007. World Development Report 2008: Agriculture for Development. Washington, DC: World Bank. .2011. Commodity Price Data (Pink Sheet). Available from: www.worldbank.org/prospects. [Accessed 3 November 2011]. . 2012. World Development Indicators 2012. (C) Washington, DC. https://openknowledge.worldbank.org/handle/10986/6014. License: CC BY 3.0 Unported.

Yu, Bingxin, and Alejandro Nin Pratt. 2011. Agricultural Productivity and Policies in Sub-Saharan Africa. IFPRI Discussion Paper 1150. Washington, DC: International Food Policy Research Institute. 




\section{RECENT IFPRI DISCUSSION PAPERS}

\section{For earlier discussion papers, please go to www.ifpri.org/pubs/pubs.htm\#dp. All discussion papers can be downloaded free of charge.}

1223. Review of input and output policies for cereals production in Pakistan. Abdul Salam, 2012.

1222. Supply and demand for cereals in Pakistan, 2010-2030. Hina Nazli, Syed Hamza Haider, and Asjad Tariq, 2012.

1221. The road to specialization in agricultural production: Evidence from Rural China. Yu Qin and Xiaobo Zhang, 2012.

1220. Change and diversity in smallholder rice-fish systems: Recent evidence from Bangladesh. Madan M. Dey, David J. Spielman, A.B.M. Mahfuzul Haque, Md. Saidur Rahman, and Rowena A. Valmonte-Santos, 2012.

1219. Is MERCOSUR's external agenda pro-poor?: An assessment of the European Union-MERCOSUR free-trade agreement on poverty in Uruguay applying MIRAGE. Carmen Estrades.

1218. Heterogeneous pro-poor targeting in India's Mahatma Gandhi national rural employment guarantee scheme. Yanyan Liu and Christopher B. Barrett, 2012.

1217. The impacts of public investment in and for agriculture: Synthesis of the existing evidence. Tewodaj Mogues, Bingxin Yu, Shenggen Fan, and Linden McBride, 2012.

1216. What determines public expenditure allocations?: A review of theories, and implications for agricultural public investment. Tewodaj Mogues, 2012.

1215. Nonlinear dynamics of livestock assets: Evidence from Ethiopia. Bjorn Van Campenhout and Stefan Dercon, 2012.

1214. An overview of Chinese agricultural and rural engagement in Tanzania. Deborah Bräutigam and Xiaoyang Tang, 2012.

1213. The partially liberalized cocoa sector in Ghana: Producer price determination, quality control, and service provision. Shashidhara Kolavalli, Marcella Vigneri, Haruna Maamah, and John Poku, 2012.

1212. Structural change in Argentina, 1935-60: The role of import substitution and factor endowments. Dario Debowicz and Paul Segal, 2012.

1211. Traceability in a supply chain with repeated moral hazard. Alexander E. Saak, 2012.

1210. Managing transition in Yemen: An assessment of the costs of conflict and development scenarios for the future. Clemens Breisinger, Olivier Ecker, Perrihan Al Riffai, Wilfried Engelke, and Abdulmajeed Al-Bataly, 2012.

1209. Bangladesh rice trade and price stabilization: Implications of the 2007/08 experience for public stocks. Paul A. Dorosh and Shahidur Rashid, 2012.

1208. Analyzing intersectoral convergence to improve child undernutrition in India: Development and application of a framework to examine policies in agriculture, health, and nutrition. Rajani Ved and Purnima Menon, 2012.

1207. Branding and agricultural value chains in developing countries: Insights from Bihar, India. Bart Minten, K.M. Singh, and Rajib Sutradhar, 2012.

1206. Costly posturing: Relative status, ceremonies, and early child development in China. Xi Chen and Xiaobo Zhang, 2012.

1205. Should private storage be subsidized to stabilize agricultural markets after price support schemes are removed?: A general equilibrium analysis applied to European reforms. Fabienne Femenia, 2012.

1204. Mapping the contemporary fertilizer policy landscape in Malawi: A guide for policy researchers. Noora-Lisa Aberman, Michael Johnson, Klaus Droppelmann, Eva Schiffer, Regina Birner, and Peter Gaff, 2012.

1203. The economic consequences of excess men: Evidence from a natural experiment in Taiwan. Simon Chang and Xiaobo Zhang, 2012.

1202. The value of customized insurance for farmers in rural Bangladesh. Daniel Clarke, Narayan Das, Francesca de Nicola, Ruth Vargas Hill, Neha Kumar, and Parendi Mehta, 2012.

1201. Gender assessment of the agricultural sector in the Democratic Republic of the Congo. Catherine Ragasa, Annie KinwaMuzinga, and John Ulimwengu, 2012.

1200. Toward an integrated approach for addressing malnutrition in Zambia: A literature review and institutional analysis. Jody Harris and Scott Drimie, 2012.. 


\section{INTERNATIONAL FOOD POLICY}

RESEARCH INSTITUTE

www.ifpri.org

IFPRI HEADQUARTERS

2033 K Street, NW

Washington, DC 20006-1002 USA

Tel.: +1-202-862-5600

Fax: +1-202-467-4439

Email: ifpri@cgiar.org 